Research Article

\title{
Effects of an Applied Load on the Chloride Penetration of Concrete with Recycled Aggregates and Recycled Powder
}

\author{
Zhiming Ma $\mathbb{D}^{1},{ }^{1,2}$ Zhenhua Duan $\mathbb{D}^{1},{ }^{1}$ and Guangzhong Ba $\mathbb{D}^{1}$ \\ ${ }^{1}$ Department of Structural Engineering, Tongji University, Shanghai 200092, China \\ ${ }^{2}$ College of Civil Science and Engineering, Yangzhou University, Yangzhou 225127, China
}

Correspondence should be addressed to Zhenhua Duan; zhduan@tongji.edu.cn

Received 31 December 2018; Revised 15 March 2019; Accepted 25 March 2019; Published 14 May 2019

Academic Editor: Lukasz Sadowski

Copyright (c) 2019 Zhiming Ma et al. This is an open access article distributed under the Creative Commons Attribution License, which permits unrestricted use, distribution, and reproduction in any medium, provided the original work is properly cited.

Recycled aggregate (RA) and recycled powder (RP) are the primary products of the reclamation of construction and demolition (C\&D) wastes, and the question of how to use them to prepare recycled aggregate concrete (RAC) and recycled powder concrete (RPC) has been a hot topic in the construction industry in China. As concrete structures are frequently subjected to the effects of both applied loads and chloride attacks, it is necessary to examine their effects on both RAC and RPC, which have received little consideration in previous investigations. In this study, RAC and RPC were firstly prepared by using RA and RP, respectively, to replace natural coarse aggregate and cement by weight. For each type of recycled concrete, sustained load and repeated load tests were then conducted, followed by a chloride diffusion experiment after unloading. The results indicated that the chloride penetration increased with the loading degree as well as the repeated load cycles. As the RP used in this study has high fineness and activity, the chloride penetration of RPC was lower than that of natural concrete, while the opposite result was found in RAC. Besides, the correlation between the chloride diffusivity and the imposed loading damage was also established in this study.

\section{Introduction}

Concrete structures are usually subjected to harsh environments, freeze-thaw cycles, chloride and sulfate attacks, etc. [1-3]. Acting as the most important indicator of durability, chloride attacks frequently cause the steel to corrode in reinforced concrete and thus decrease the service life of the concrete structure $[4,5]$. About $80 \%$ of the structural failure was caused by the chloride penetration in the reinforced concrete according to the statistics [6]. Steel corrosion induced by chloride penetration is generally considered as a durability issue of the reinforced concrete around the world, especially for some environmental considerations $[7,8]$. Moreover, the chloride penetration behavior is closely related to the mix proportion, pore structure, water content, and the exposed environment of concrete.

In practice, the concrete elements are inevitably subjected to loading conditions, and the properties of natural concrete (NC) with the coupling effect of applied loads and chloride penetration have been widely investigated. Wang et al. [9] and $\mathrm{Ma}$ et al. [10] investigated the impacts of sustained loads on the chloride diffusivity of $\mathrm{NC}$, and the results indicated that the chloride penetration behavior is significantly influenced by relatively high levels of loads. A study conducted on the chloride diffusivity after unloading showed that the permeability increased with an increase in preload levels [11]. For loads that exceed $60 \%$ of the ultimate compressive load, Saito and Ishimori [12] demonstrated that the chloride penetration behavior of concrete is significantly increased with an increase in the repeated load cycles. Furthermore, Wang et al. [9], He and Gong [13], and Ye et al. [14] found that an increase in flexural loads resulted in an increase of chloride penetration behavior. Several mathematical models and new testing methods have been developed to reveal the chloride migration in concrete with compressive loads or cracks [15-17]. The use of cementitious materials or fibers is able to reduce the penetration of chloride ions into mortar or concrete, which may be helpful to improve the durability under applied load condition [18-20]. 
With the rapid development of economy and construction industry, large amounts of construction and demolition (C\&D) wastes are being produced, and it was estimated that about 1.8 billion tons of C\&D wastes were produced in China in 2017 [21, 22]. The disposal of such C\&D wastes at landfills will inevitably induce a series of environmental problems, since the C\&D wastes may contain hazardous substances, leading to land occupation, water pollution, etc. $[23,24]$. The amount of waste concrete and bricks accounts for $70-90 \%$ of the total amount of C\&D wastes [25], so technologies have been proposed to crush the C\&D wastes into recycled aggregate (RA) or recycled powder (RP), which can be used as alternatives to natural aggregate (NA) or cement to prepare recycled aggregates concrete (RAC) or recycled powder concrete (RPC), respectively. The properties of RAC have been deeply investigated, and it has been shown that the alternative use of RA generally decreases the mechanical properties [26-29] and aggravates the durability degeneration of concrete; for example, a significant rise can be noticed for the chloride diffusivity of RAC with an increase in RA content [30, 31]. Due to the relatively high water absorption, the effective reuse of recycled fine aggregate (RFA), as well as the RP produced in the production of RA, is a major problem.

In recent years, many researchers have attempted to develop RP of ultrafine particles through further processing of RFA and waste powder to partially replace the cement in concrete. As reported in $[32,33]$, there are some active substances and high $\mathrm{SiO}_{2}$ content in RP that has been prepared from C\&D wastes, and the properties of the concrete are little affected when the RP replaces up to $15 \%$ of the cement. Furthermore, a study conducted by Xiao et al. [22] demonstrated that the use of RP in concrete might reduce its workability and increase the risk of early age cracking, even though the mechanical properties were slightly improved. The chloride ion penetration behavior is closely related to the water content in concrete, which is an important medium for the migration of chloride ion [10, 34]. Gao et al. [35] found that the water penetration behavior of RAC was greatly affected by the imposed loading damage that increased much higher than that of NC after suffering the same load history. It suggests that the chloride penetration behavior of RAC may be also impacted by the applied loads that further investigation should be conducted. However, for the chloride diffusivity of RAC and RPC, the effects of applied loads were received little consideration in the previous investigations.

Considering that RAC and RPC may be inevitably subjected to the dual influence of applied load and chloride erosion in practical application, this study aims to investigate the effects of applied loads on the chloride penetration behavior of RAC and RPC firstly, and each dosage of $\mathrm{RP}$ and RP, together with the types and levels of applied loads, was considered as the main parameter. Additionally, the relationships between the chloride diffusivity and the induced loading damage were also established to provide some necessary data for the design of more durable recycled concrete.

\section{Materials and Methods}

As shown in Figure 1, the chloride penetration behavior of RAC and RPC with preload damage, including a sustained compressive load and repeated compressive load, was mainly examined in this study. Firstly, concrete with different dosages of RA and RP were prepared with the fundamental characteristics of RAC and RPC determined. Then, different types and levels of compressive loads were applied to RAC and RPC specimens, respectively, to induce the corresponding loading damages, the effects of which on the chloride penetration behavior of RAC and RPC were carried out through the chloride diffusivity test after unloading.

2.1. Properties of $R A$ and $R P$. RA (5-25 mm) adopted in this study was almost entirely produced by crushing waste concrete and waste brick. The fundamental characteristics of RA were determined according to the Chinese standard "Recycled coarse aggregate for concrete" (GB25177-2017), and their adhered old mortar content was obtained by using the acid pickling method [36,37]. As shown in Figure 2(a), the size distribution of RA meets the requirements of the Chinese standard "Pebble and crushed stone for building" (GB14685-2001). Although the grading curves of RA and NA both meet the requirement of the Chinese standard, the particle size of RA is generally higher than that of NA. Table 1 gives a comparison on the properties of RA and NA, and it can be noticed that the properties of RA are generally weaker than those of NA due to the presence of adhered old mortar, which has a mass of initial cracks and pores. It is worth noting that the water absorption of RA adopted in this study is about 4.3 times higher than that of NA, which should be considered during mix design and concrete preparation.

In China, brick-concrete buildings are a common building type in most areas, and many are currently being demolished, among which the waste brick and waste concrete account for $70-90 \%$ of the total waste [25]. The C\&D wastes were also used to produce RP by a fine grinding treatment, and the produced RP can be used to replace part of the supplementary cementitious materials to produce RPC. As regards the RP examined in this study, its particle size distribution (Figure 2(b)) was determined by a particle size analyzer, and it was found that particle sizes below $45 \mu \mathrm{m}$ accounted for about 92\%, which meets the requirements for class I powder in terms of the Chinese standard GB1596-2005. Furthermore, the RP's average particle size $(9.06 \mu \mathrm{m})$ was even lower than that of OPC, while its specific surface area, $639.6 \mathrm{~m}^{2} / \mathrm{kg}$, was about 1.83 times larger than that of OPC. Figure 2(c) further gives the SEM images of RP, and the typical microstructure of $\mathrm{SiO}_{2}$, C-S-H, and $\mathrm{Ca}(\mathrm{OH})_{2}$ can be seen. Furthermore, Figure 2(d) gives a comparison on the chemical composition of RP, fly ash, and OPC, and the results highlight that the chemical composition contents of RP is between that of fly ash and OPC, which proves the RP can be used as a substitute of the supplementary cementitious materials. 


\begin{tabular}{|c|c|c|c|}
\hline $\begin{array}{l}\text { RAC with RA replacement of } \\
0 \%, 33 \%, 66 \% \text {, and } 100 \%\end{array}$ & * Hydration heat & $\begin{array}{l}\text { Sustained compressive load } \\
0 \% f_{\mathcal{c}}, 40 \% f_{\mathcal{c}}, 60 \% f_{\mathcal{c}} \text {, and } 80 \% f_{\mathrm{c}}\end{array}$ & Chloride diffusivity test after unloading \\
\hline & * Compound composition & & * Surface chloride content \\
\hline $\begin{array}{l}\text { RPC with RP replacement of } \\
0 \%, 15 \%, 30 \% \text {, and } 45 \%\end{array}$ & * Compressive strength & $\begin{array}{l}\text { Repeated compressive load } \\
0,1,10,20 \text {, and } 30 \text { times }\end{array}$ & * Chloride diffusion coefficient \\
\hline 1. concrete preparation & 2. basic performance & 3. applied loading test & 4. chloride penetration test \\
\hline
\end{tabular}

FIgURE 1: Flow chart of the chloride diffusivity test for RAC and RPC with preload damage.

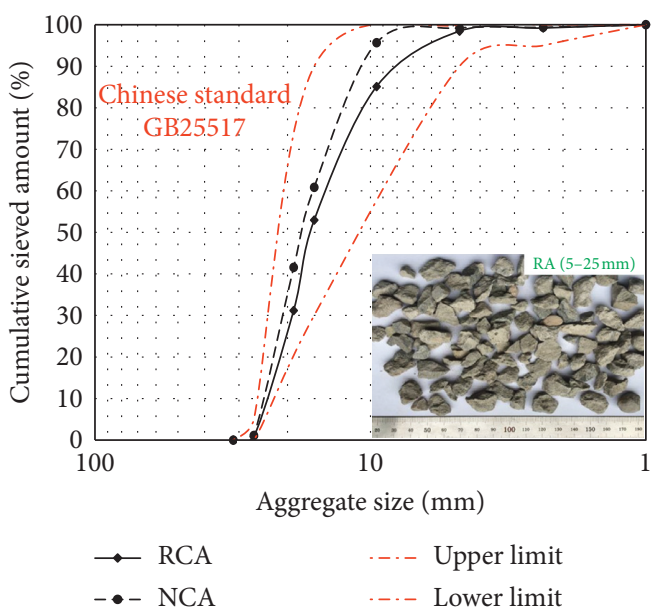

(a)

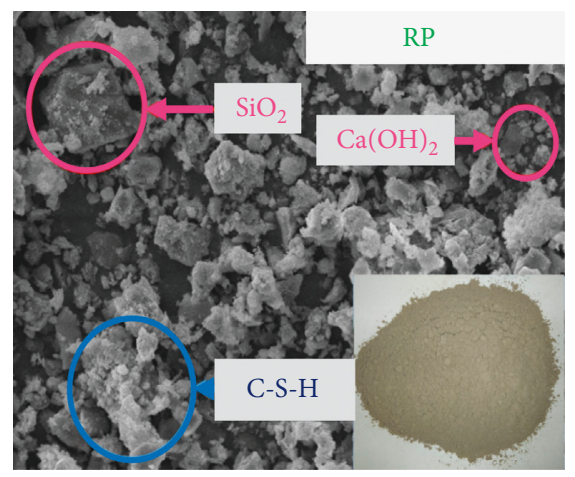

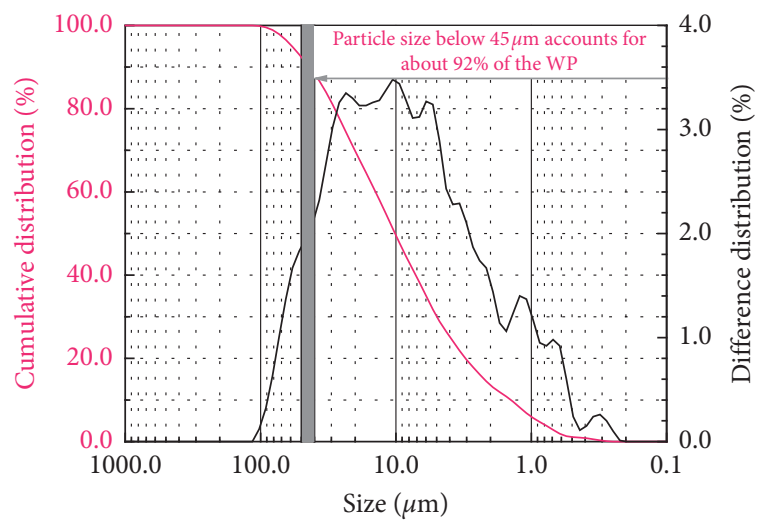

(b)

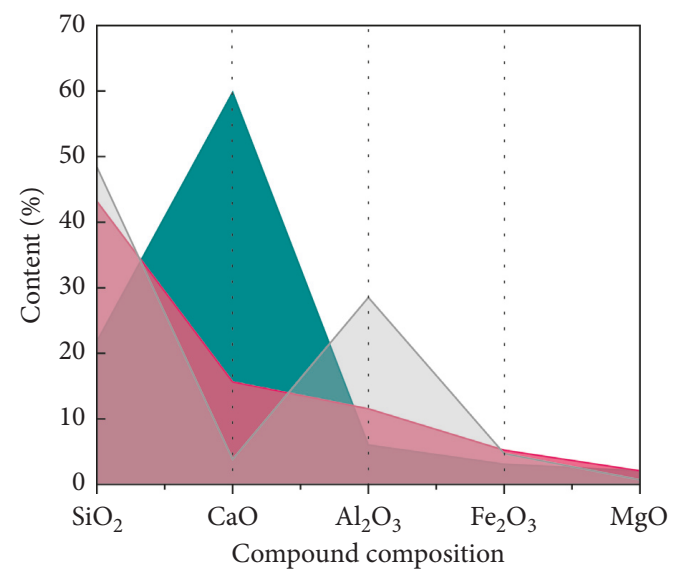

Cement

Recycled powder

Fly ash

(c)

(d)

FIGURE 2: Size distribution of (a) recycled coarse aggregate and (b) recycled powder. (c) SEM images of recycled powder. (d) The comparison on the chemical composition of recycled powder, fly ash, and cement.

Table 1: Properties of RA and NA.

\begin{tabular}{lcc}
\hline Properties & RA & NA \\
\hline $\begin{array}{l}\text { Content of adhered old mortar (\%) } \\
\text { Packing density }\left(\mathrm{kg} / \mathrm{m}^{3}\right)\end{array}$ & 33 & 0 \\
$\quad$ Loose packing density & 1280 & 1360 \\
$\quad$ Tight packing density & 1440 & 1480 \\
Apparent density $\left(\mathrm{kg} / \mathrm{m}^{3}\right)$ & 2530 & 2660 \\
Crushing value index $(\%)$ & 11 & 5.13 \\
Clay content $(\%)$ & 1.8 & 0.8 \\
Water absorption $(\%)$ & 5.3 & 1.0 \\
\hline
\end{tabular}

2.2. Mixture Proportions. Referring to the mix proportions of some previous studies on RAC, RPC, and concrete with supplementary cementitious materials $[22,38,39]$, the replacement percentages of RA are selected as $0,33 \%, 66 \%$, and $100 \%$, while those of RP are $0 \%, 15 \%, 30 \%$, and $45 \%$, respectively, in this study. The water-to-binder ratios (w/b) of RAC and RPC are 0.5, and the specific mix proportions are given in Tables 2 and 3, respectively. The notation RAC$\mathrm{X} / \mathrm{RPC}-\mathrm{X}$ represents that the concrete was prepared with $\mathrm{NA} /$ cement that was replaced by RA/RP at a replacement 
TABLE 2: Mix proportions of RAC $\left(\mathrm{kg} / \mathrm{m}^{3}\right)$.

\begin{tabular}{|c|c|c|c|c|c|c|}
\hline Notation & $\mathrm{w} / \mathrm{b}$ & Water & Cement & Sand & NA & RA \\
\hline RAC-0\% & \multirow{4}{*}{0.5} & \multirow{4}{*}{180} & \multirow{4}{*}{360} & \multirow{4}{*}{650} & 1190 & 0 \\
\hline RAC-33\% & & & & & 797 & 393 \\
\hline RAC- $66 \%$ & & & & & 404 & 786 \\
\hline RAC- $100 \%$ & & & & & 0 & 1190 \\
\hline
\end{tabular}

TABLE 3: Mix proportions of RPC $\left(\mathrm{kg} / \mathrm{m}^{3}\right)$.

\begin{tabular}{|c|c|c|c|c|c|c|c|c|}
\hline Notation & $\mathrm{w} / \mathrm{b}$ & Water & Cement & $\mathrm{RP}$ & Sand & NA & WRA & Slump value $(\mathrm{mm})$ \\
\hline RPC-0\% & & & 360 & 0 & & & 1.28 & 90 \\
\hline RPC-15\% & 05 & 180 & 306 & 54 & 650 & 1190 & 3.23 & 90 \\
\hline RPC-30\% & 0.5 & 180 & 252 & 108 & 650 & 1190 & 5.89 & 95 \\
\hline RPC- $45 \%$ & & & 198 & 162 & & & 8.32 & 90 \\
\hline
\end{tabular}

ratio of $X$ by mass. The secondary mixing method was used to prepare the RAC. As RA used had a relatively high water absorption rate, additional water was firstly mixed with RA to pre-wet it, with the other materials added subsequently.

For all of the mixtures, the target slump was maintained at approximately $90 \pm 5 \mathrm{~mm}$ by adjusting the amount of polycarboxylate water reducer (Sunray Ltd. in Shanghai). After the mixing and workability test, cube specimens of $100 \times 100 \times 100 \mathrm{~mm}^{3}$ were cast and the demolded specimens were cured at a temperature of $20 \pm 2^{\circ} \mathrm{C}$ with the relative humidity of about $95 \%$ for 7,28 , and $56 \mathrm{~d}$. As RP used in this study has a high water demand due to its irregular and porous microstructure, an increasing amount of water reducer was required for the RPC with a higher content of RP to achieve a similar target slump value, as shown in Table 3 . For each testing condition, three specimens were tested to obtain the average value of each required age.

2.3. Sustained Load and Repeated Load Tests. Two types of compressive loads, sustained compressive load and repeated compressive load, were adopted in this study. For the sustained load test, four levels of load, $0 \%$ (without an applied load), $40 \%, 60 \%$, and $80 \%$ of the ultimate compression load $\left(f_{c}\right)$, were considered. The applied loading test, in accordance of the Chinese standard of GB50081-2002, is shown in Figure 3(a). As regards the repeated load test, only one level$60 \%$ of the ultimate compression load was adopted with different cycles $(0,1,10,20$, and 30$)$, and the repeated load curves can be seen from Figure 3(b). After each test, the applied loads were unloaded, and the corresponding imposed damage to RAC and RPC was determined by an ultrasonic concrete tester.

The relative dynamic elastic modulus $\left(E_{\mathrm{rd}}\right)$ is closely related to the numbers of cracks and pores in concrete, and it is frequently used to quantize the induced damage to concrete exposed to a load condition or a harsh environment. Meyers [40] gave the relationship between the ultrasonic wave velocity and dynamic elastic modulus, as shown in equation (1). Tegguer et al. [41] further proposed a method of determining the loading damage of concrete with the uniaxial compressive loading by the relative ratios of modulus in elasticity, as shown in equation (2):

$$
\begin{aligned}
& C=\sqrt{\frac{E_{\mathrm{rd}}(1-v)}{p(1-2 v)(1+v)}}, \\
& D=1-E_{\mathrm{rd}}=1-\frac{E}{E_{0}}=1-\left(\frac{C_{i}}{C_{0}}\right)^{2}=1-\left(\frac{T_{0}}{T_{i}}\right)^{2},
\end{aligned}
$$

where $C$ is the ultrasonic wave velocity; $E_{\mathrm{rd}}$ stands for the relative dynamic elastic modulus; $p$ presents the concrete density; $v$ is Poisson's ratio; $D$ means the damage level of the load; $E$ and $E_{0}$ represent the elastic modulus of the concrete with and without an applied load, which can be obtained by the values of the sonic time or the wave velocity; and $T_{i}$ and $T_{0}$ are the sonic time with and without an applied load.

2.4. Chloride Diffusion Test. The chloride diffusion test was carried out on the specimens after removing the load, and Figure 3(c) shows a flow chart for the chloride diffusion test. For each mixture, a specimen with a certain amount of preload damage was firstly placed in $5 \% \mathrm{NaCl}$ solution for 60 days, and then it was oven-dried until it showed no further variation in mass. Immediately after that, one layer of the specimen with a thickness of 2-5 mm, exposed adequately to the $\mathrm{NaCl}$ solution, was milled to obtain a concrete powder, which was then mixed with the distilled water for $24 \mathrm{~h}$ to make the free chloride ion dissolve completely. Then, the chloride content of the obtained solution was determined using the chloride ion selective electrode (ISE) method in accordance with the Chinese standard "Technical specification for test of chloride ion content in concrete" (JGJ322-2013). The chloride ion diffusion behavior in the saturated concrete can be described by Fick's second law, as shown in equation (3), while the force of chloride diffusion is mainly provided by the difference in chloride concentration; moreover, the chloride diffusion coefficient can be obtained by the data fitting for the chloride ion content $[5,42,43]$ : 

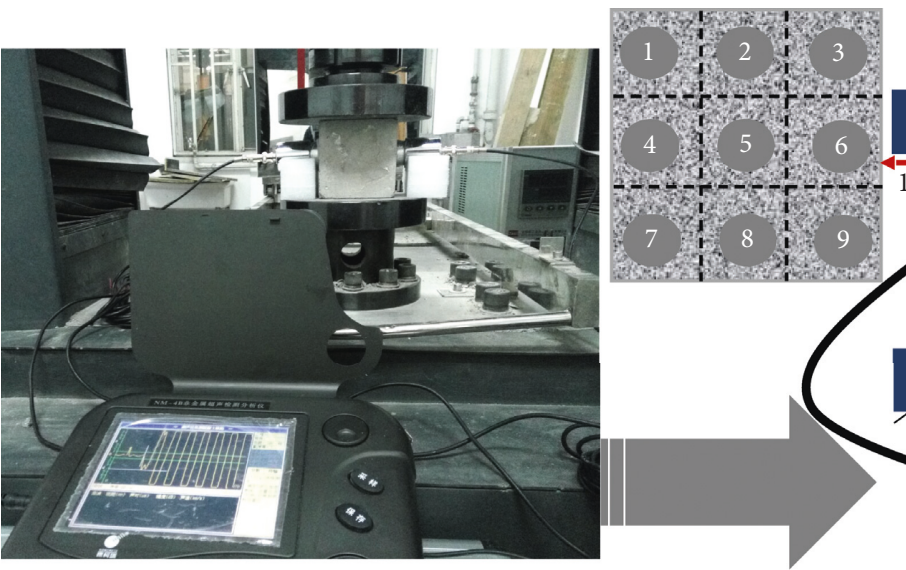

(a)

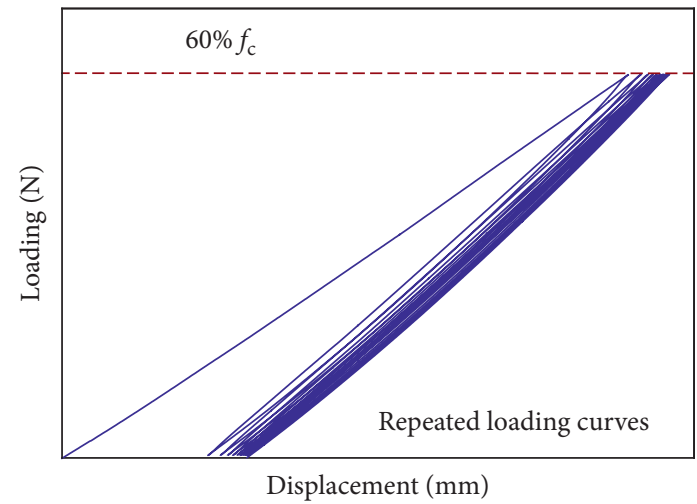

(b)

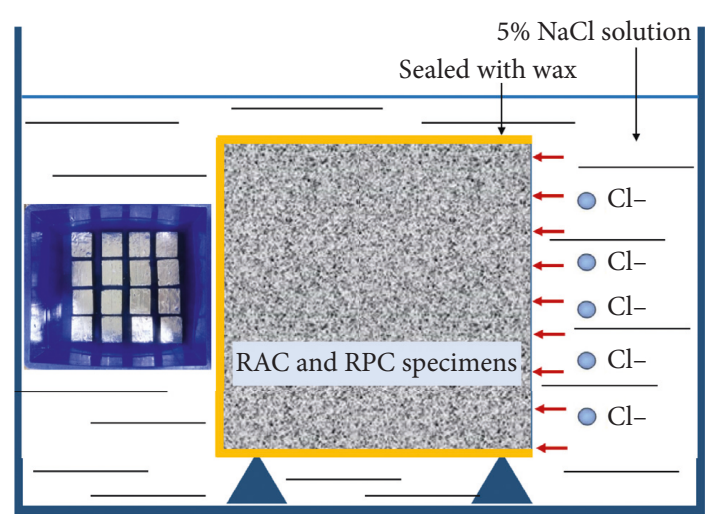

(c)

Figure 3: Test methods and equipment. (a) The loading test and the testing method for imposing load damage. (b) Repeated loading curves. (c) Chloride ion diffusion test.

$$
C(x, t)=C_{0}+\left(C_{\mathrm{s}}-C_{0}\right)\left[1-\operatorname{erf}\left(\frac{x}{2 \sqrt{D_{\mathrm{ap}} \cdot t}}\right)\right]
$$

where $C(x, t)$ stands for the chloride ion content at a depth $x$ $(\mathrm{m})$ and exposure time $t(\mathrm{~s}) ; C_{\mathrm{S}}(\%)$ represents the surface chloride content; $C_{0}(\%)$ is the initial chloride content of the concrete; and $D_{\text {ap }}$ means the chloride diffusion coefficient $\left(10^{-12} \mathrm{~m}^{2} / \mathrm{s}\right)$, which can be obtained by fitting chloride profiles with the least-squares method.

\section{Results and Discussion}

3.1. Fundamental Characteristics of RAC and RPC. The compressive strength of concrete with various amounts of RA content is shown in Table 4. As is generally accepted, the compressive strength of RAC reduced with an increase in the RA replacement ratio. After 28 days of curing, the reduction in the compressive strength was found to be about $4 \%, 8 \%$, and $15 \%$ for the RA replacement ratios $33 \%, 66 \%$, and $100 \%$, respectively. This can be attributed to the inferior properties of the adhered old mortar and the ITZ on RA, which has many initial cracks and flaws that aggravate the degeneration of the concrete's mechanical properties under compressive loading.
The hydration heat test in compliance with the Chinese standard "Test methods for heat of hydration of cement" (GB12959-2008), along with the thermogravimetric analysis and chemical composition tests, was conducted to investigate the effects of RP on the properties of the binding materials, and the results are shown in Figure 4 [33]. As can be seen in Figure 4(a), the addition of RP improves the hydration reaction and results in a decrease in the heat peak time of the binding materials, since RP with the high fineness has a high activity and may promote the hydration reaction of the binding material. The maximum heat flux of the RPcement mixture is even higher than that of the control cement paste when the RP replacement ratio is $12.5 \%$, and then it decreases with a further increase in the replacement ratio. Particularly, the heat flux with a 50\% RP replacement ratio reduces sharply: only $72.6 \%$ of that of the control cement paste. This can be attributed to the reduction of $\mathrm{CaO}$ in RP, which slows down the hydration reaction, especially when the mixture contains a high volume of RP.

Figure 4(b) shows the thermogravimetric analysis (TGA) results of RPC after 28 days of curing, which highlights three endothermic peaks on the curves. The first peak for all of the mixtures occurs at the decomposition stage of C-S-H and ettringite with a temperature of $80-130^{\circ} \mathrm{C}$. The paste with $25 \%$ RP replacement ratio possesses the highest peak value, 
TABLE 4: Compressive strength of RAC (MPa).

\begin{tabular}{lcccccrrr}
\hline Curing time & RAC-0\% & SD & RAC-33\% & SD & RAC-66\% & SD & RAC-100\% & SD \\
\hline $28 \mathrm{~d}$ & 34.8 & 1.89 & 33.5 & 2.35 & 32.2 & 1.68 & 30.3 & 3.27 \\
$56 \mathrm{~d}$ & 38.9 & 1.37 & 37.7 & 2.04 & 36.4 & 2.47 & 33.6 & 2.23 \\
\hline
\end{tabular}

SD represents the standard deviation of the compressive strength values.

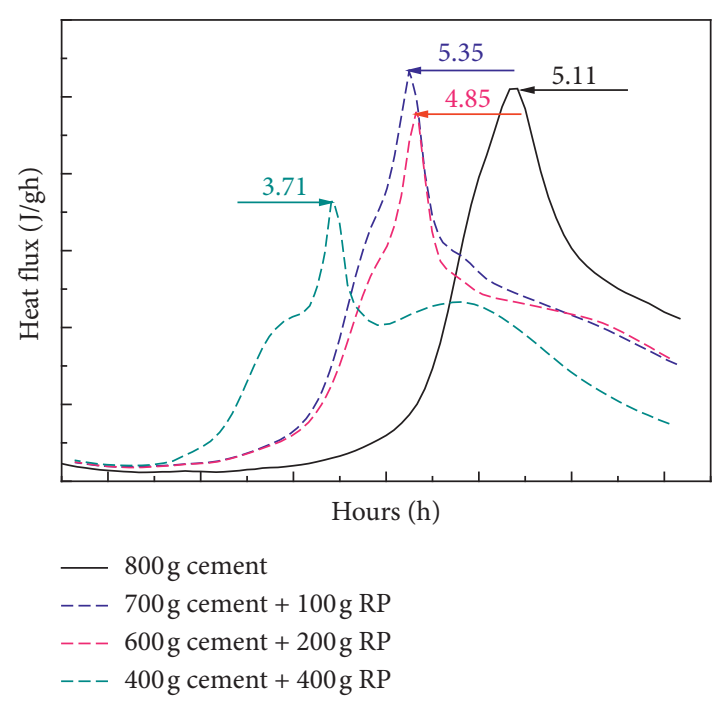

(a)

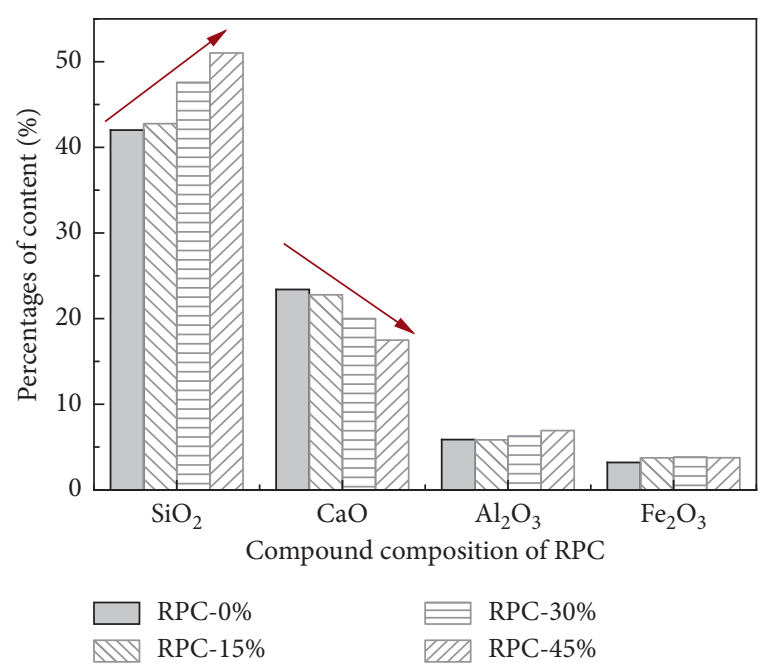

(c)

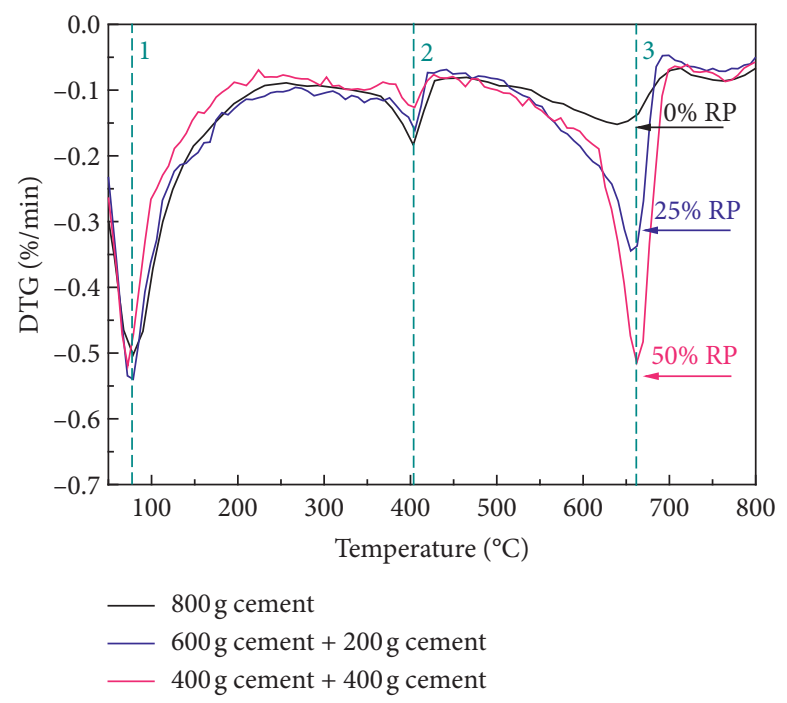

(b)

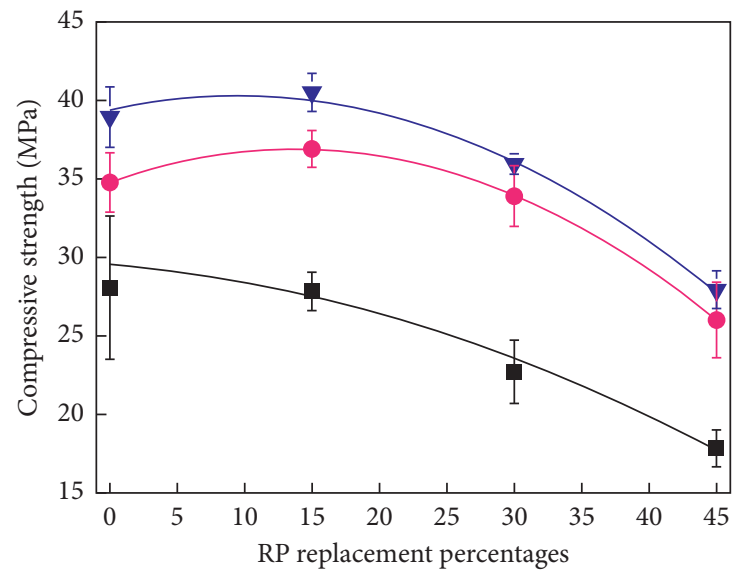

- After $7 \mathrm{~d}$ curing

- After $14 \mathrm{~d}$ curing

$\nabla$ After $28 \mathrm{~d}$ curing

(d)

Figure 4: Properties of concrete with various amounts of RP content. (a) The hydration heat curve of the cement and RP mixture. (b) The thermogravimetric test result of the cement and RP mixture. (c) The compound composition of RPC. (d) The compressive strength of RPC.

indicating that an appropriate content of RP is beneficial to improve the hydration reaction of the binding materials. The second endothermic peak occurs at the decomposition stage of $\mathrm{Ca}(\mathrm{OH})_{2}$ into $\mathrm{CaO}$ and $\mathrm{H}_{2} \mathrm{O}$ with a temperature of $400-500^{\circ} \mathrm{C}$, which highlights that the alterative use of RP leads to a reduction in the $\mathrm{Ca}(\mathrm{OH})_{2}$ in pastes. The third endothermic peak happens at the decomposition stage of $\mathrm{CaCO}_{3}$ into $\mathrm{CaO}$ and $\mathrm{CO}_{2}$ with a temperature of approximately $700^{\circ} \mathrm{C}$. As the main composition of $\mathrm{RP}$ is $\mathrm{CaCO}_{3}$, the peak strength of the third endothermic peak increases with an increase in the replacement percentage of RP.

Figure 4(c) shows the compound composition of concrete mixed with various amounts of RP via the X-ray fluorescence test. The results highlight the increase in the content of $\mathrm{SiO}_{2}$ as more RP is added. This is because RP is mainly produced by the grinding of waste concrete and bricks, which contain a mass of $\mathrm{SiO}_{2}$. Therefore, replacing the cement whose main content is $\mathrm{CaO}$, by the same weight 
of RP, significantly enhances the $\mathrm{SiO}_{2}$ content and meanwhile reduces the $\mathrm{CaO}$ content in concrete. The addition of $\mathrm{RP}$ results in a decrease in the hydration products of the binding materials, especially for the concrete mixed with a high volume of $\mathrm{RP}$, because $\mathrm{CaO}$ is the main component that takes part in the hydration reaction.

Figure 4(d) shows the compressive strength of RPC with various amounts of RP content after 28 days and 56 days curing, respectively. Similar trends can be noticed for RPC at different curing ages. When the replacement percentage of $\mathrm{RP}$ is below $30 \%$, the compressive strength of RPC is equal or even higher than that of NC. However, for RPC prepared with $45 \% \mathrm{RP}$, the compressive strength drops greatly when compared with that of NC. This is mainly due to the improvement in the concrete's density by the use of RP, in which the compressive strength is correspondingly increased when the RP replacement in concrete is no more than $30 \%$. When the RP replacement reaches $45 \%$, the compressive strength significantly decreases due to the reduction of hydration products in the concrete.

\subsection{Chloride Diffusivity of RAC and RPC without Preloading} Damage. The chloride penetration behavior of RAC without the preloading damage was determined, and the results are described in Figure 5. The surface chloride content and the chloride diffusion coefficient of concrete increased with the increase of RA content, and the increase in both cases is proportional to the RA replacement percentage, as shown in Figure 5(b). The addition of RA enhances the chloride diffusivity of concrete. It can be explained as follows. On the one side, the inferior properties of RA, with a number of initial cracks and pores, result in an increase in the total porosity of the concrete, which provides more passageways for chloride penetration into RAC [44]. On the other side, the ITZ, with a loose structure and initial cracks, also reduces the chloride diffusivity resistance of RAC. Furthermore, Qin and Yang [45] determined that the chloride diffusion coefficient of the ITZ in the RA is about 5 times higher than that in the NA by a chloride diffusion test on the modeled RAC. The low resistance to the chloride penetration of RAC is mainly contributed to the inferior properties of the adhered old mortar, the removal of which is beneficial to enhance the resistance of RAC to the [36].

As regards the RPC that was prepared with various amounts of RP content, Figures 6(a) and 6(b) show the influence of the RP content on the surface chloride content and the chloride diffusion coefficient of RPC, respectively. In the case where the RP replacement percentage is no more than $30 \%$, it is worth noting that an increase in RP content leads to reductions in both the surface chloride content and the chloride diffusion coefficient of concrete. For concrete with $45 \%$ RP replacement, the surface chloride content and the chloride diffusion coefficient are both higher than those of concrete with $30 \%$ RP replacement. The results also highlight that the concrete with $30 \% \mathrm{RP}$ replacement possesses the best resistance to chloride diffusivity.

As RP has relatively high fineness and activity, it is possible that the hydration reaction of the mixed binding materials may be improved when RP is used to replace part of the cement, as presented in Figures 4(a) and 4(b). In addition, RP microparticles can be regarded as a filling material and possess a microaggregate filling effect that can fill the pores and cracks in the concrete, increasing the density and decreasing the porosity of the concrete. This can be used to explain why the use of RP as an alternative reduces the chloride diffusivity of concrete. However, when the replacement ratio of cement to RP is too high ( $45 \%$, for example), the number of hydration products drops significantly and an increase in the number of pores and cracks occurs. In this case, the positive effects that are caused by the RP's filling effect cannot offset the adverse effects that are caused by the decrease in the number of hydration products in the concrete. Therefore, there is a final increase in the chloride diffusivity.

\subsection{Chloride Diffusivity of RAC with Preloading Damage.} Figure 7 shows the damage level of RAC with various applied loads $(0,40 \%, 60 \%$, and $80 \%$ of the ultimate compressive load). It can be clearly noticed that the damage level increases with an increase in the applied load, and the increase becomes more obvious when the applied load is above $60 \%$ of the compressive load. After suffering the same load history, the damage level increases with an increase in the RA content in the concrete. This suggests that RA has a negative impact on the properties of concrete under an applied load. This is due to the adhered old mortar and the ITZ of RA that contain a number of initial flaws, which are prone to form new cracks in the concrete under a compressive load.

Figure 8 presents the chloride content curves and the chloride diffusion coefficient of RAC after various levels of sustained load. The results show that the surface chloride content and the chloride diffusion coefficient both increase as the loading levels increase, especially when the applied loads exceed $60 \%$ of the ultimate compressive load. After suffering the same load history, the surface chloride content and the chloride diffusion coefficient of RAC-100\% are higher than those of NC, and the deference becomes more significant as the loading levels increase. Similar to NC, the increased load levels result in an increase in the numbers and widths of microcracks, which provides more passageways for chloride to permeate from the microcracks to RAC [41]. Furthermore, the higher load levels and repeated load cycles, which produce more cracks and flaws, further enhance the permeability of the concrete [46]. Thereby, the chloride diffusivity increases as the applied load increases. However, the properties of RAC are more sensitive to the loading compared with those of $\mathrm{NC}[36,47]$ due to the inferior properties of the adhered old mortar and the ITZ of RA. It is easier for cracks to form and develop in RAC than in NC exposed to the same loading levels, which results in the chloride diffusivity of RAC- $100 \%$ being higher than that of NC.

Figure 8 also shows the chloride content curves and the chloride diffusion coefficient of RAC after various cycles of repeated load. The results highlight that the surface chloride 


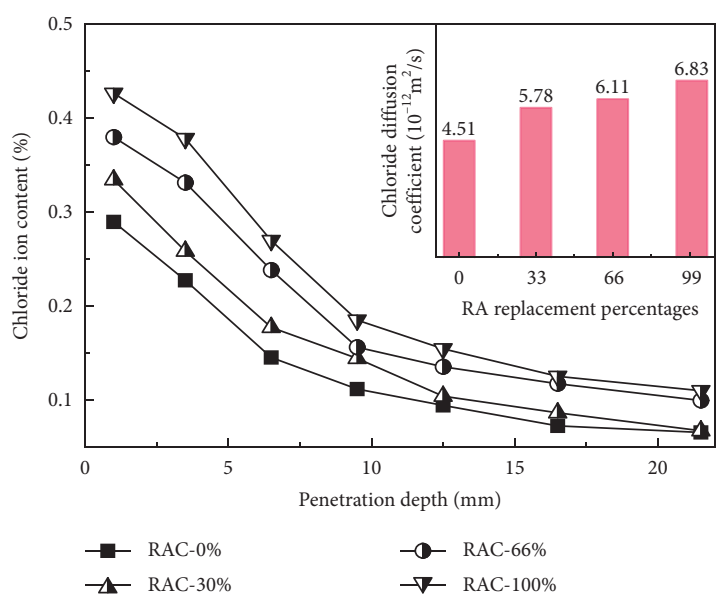

(a)

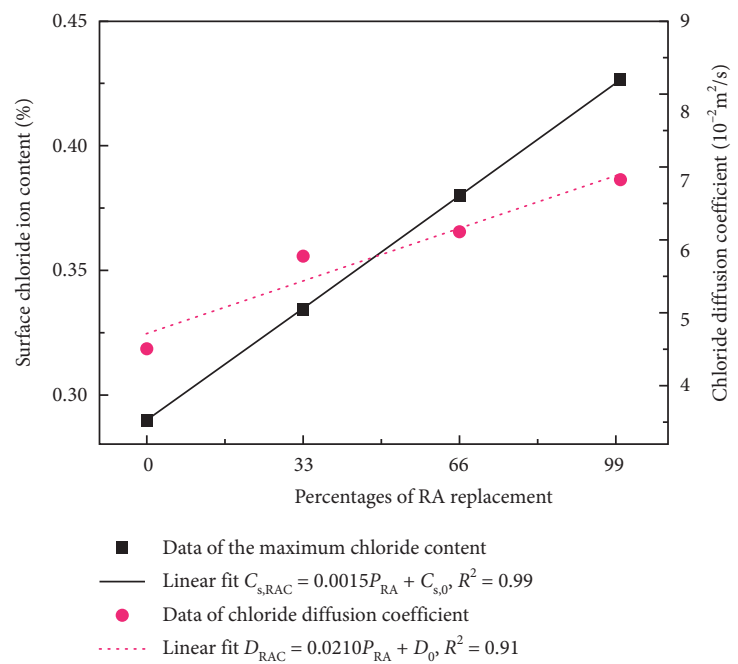

(b)

FIgURE 5: Chloride diffusivity of RAC without preloading damage. (a) The chloride content curves of RAC. (b) The correlation between RA content and the chloride diffusivity of the concrete.

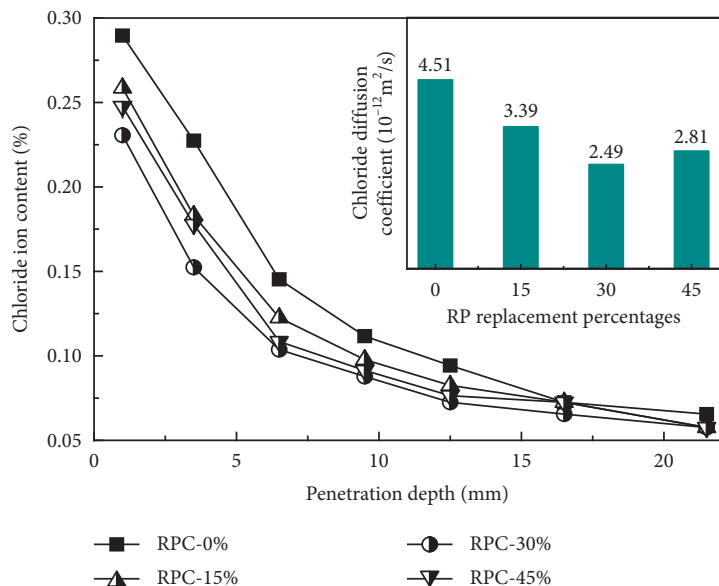

(a)

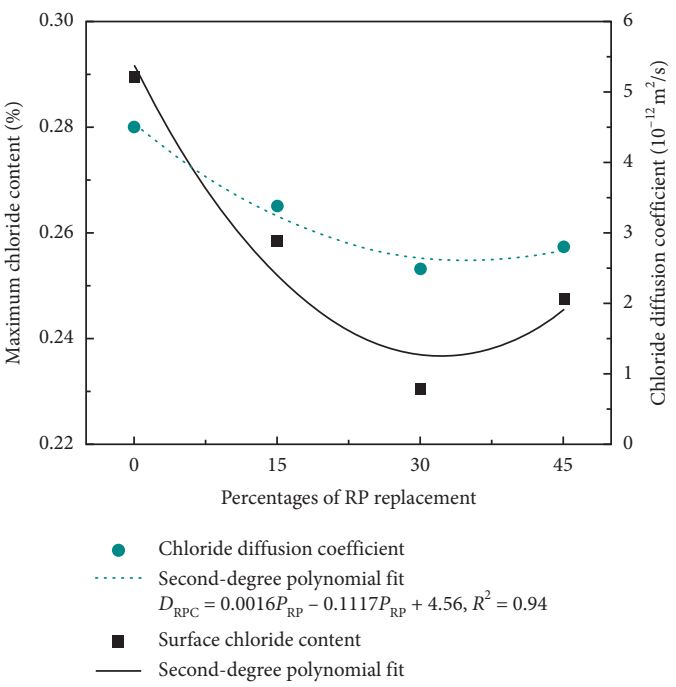

(b)

FIgURE 6: The chloride diffusivity of RPC without preloading damage. (a) The chloride content curves of RPC. (b) The correlation between the chloride diffusivity and RP replacement ratios.

content and the chloride diffusion coefficient both increase as the repeated load cycles increase, and the increase is the most obvious during the first cycle of repeated load. For RAC-100\%, the surface chloride content after 1, 10, 20, and 30 repeated load cycles is $1.17,1.24,1.30$, and 1.32 times, respectively, higher than that without preloading, and the results become 1.41, 1.49, 1.60, and 1.69 times, respectively, higher than that without preloading for the chloride diffusion coefficient of RAC. Sun [48] found that the cracks in concrete keep on developing with an increase in the repeated load cycles when the applied load reaches $60 \%$ of the ultimate compressive load. Thereby, increases in the cycles of repeated load lead to increases in the chloride diffusivity of RAC. However, due to the existence of initial cracks and flaws in the adhered old mortar and the ITZ of RA, it is easier for cracks in RAC to form and develop than in NC. Thereby, the surface chloride content and the chloride diffusion coefficient both increase as the RA content in the concrete increases, after suffering the same repeated load histories.

Figure 9 describes the correlation between the chloride diffusion coefficient and the damage level (D) of RAC. The results highlight that the chloride diffusion coefficient rises linearly as the damage level grows, and the addition of RA leads to an increase in the straight fitting slope, which shows that the use of RA improves the sensitivity of chloride diffusivity under an applied load condition. The specific equation is also described in Figure 9, where $D_{\mathrm{RAC}, \mathrm{L}}$ and $D_{\mathrm{RAC}, 0}$ are the chloride diffusion coefficients of RAC with 


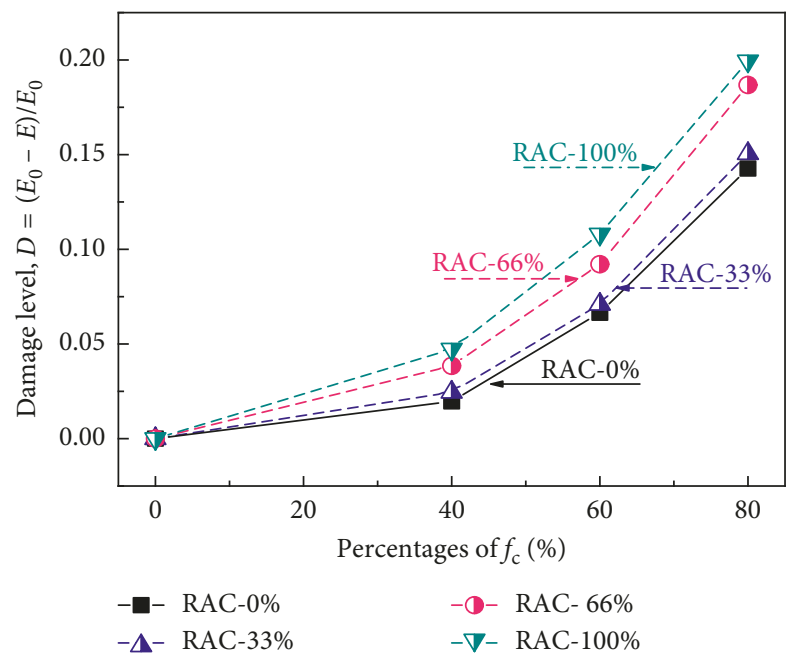

FIGURE 7: Damage level of RAC after being subjected to various loading levels.

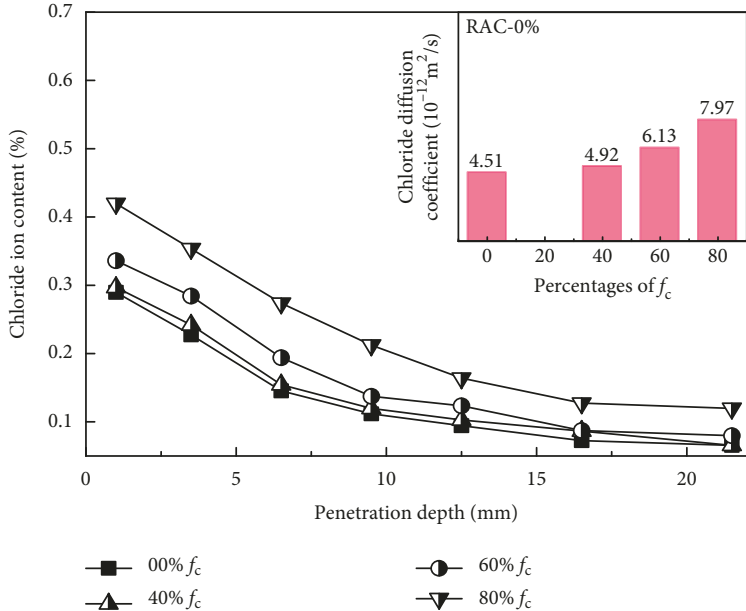

(a)

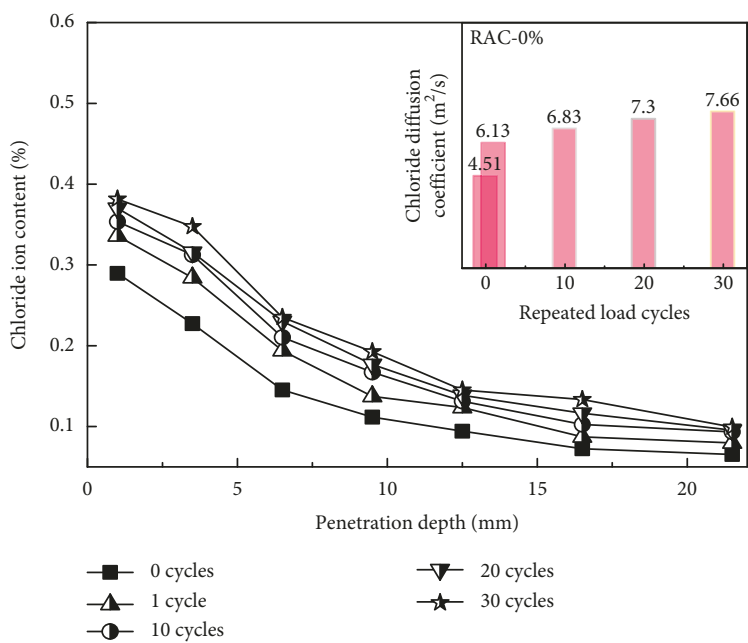

(c)

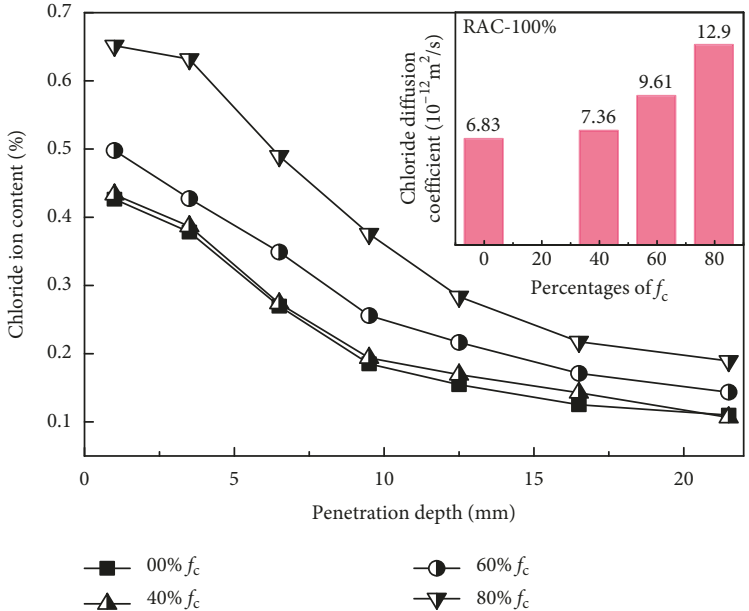

(b)

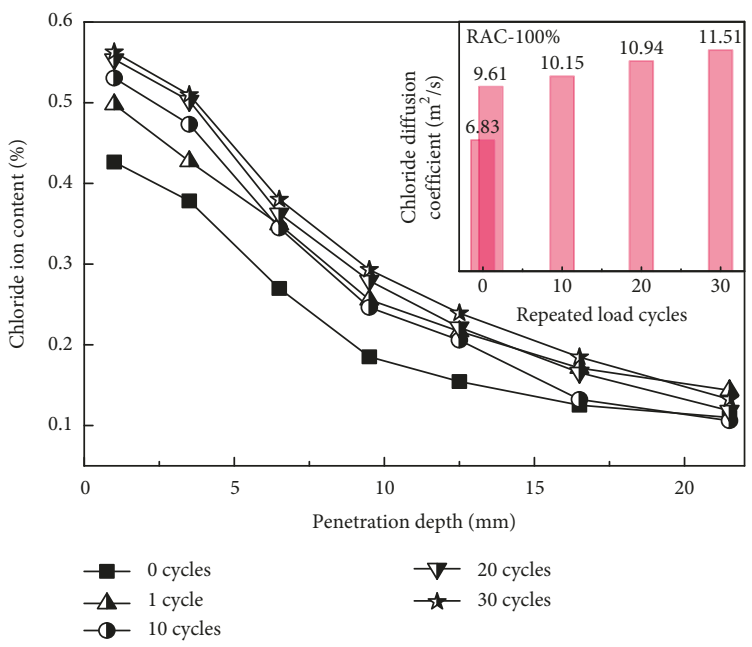

(d)

FIGURE 8: Chloride content curves of RAC with various applied loads. (a) RAC-0\% and (b) RAC-100\% after various levels of sustained load. (c) RAC- $0 \%$ and (d) RAC- $100 \%$ after various cycles of repeated load. 


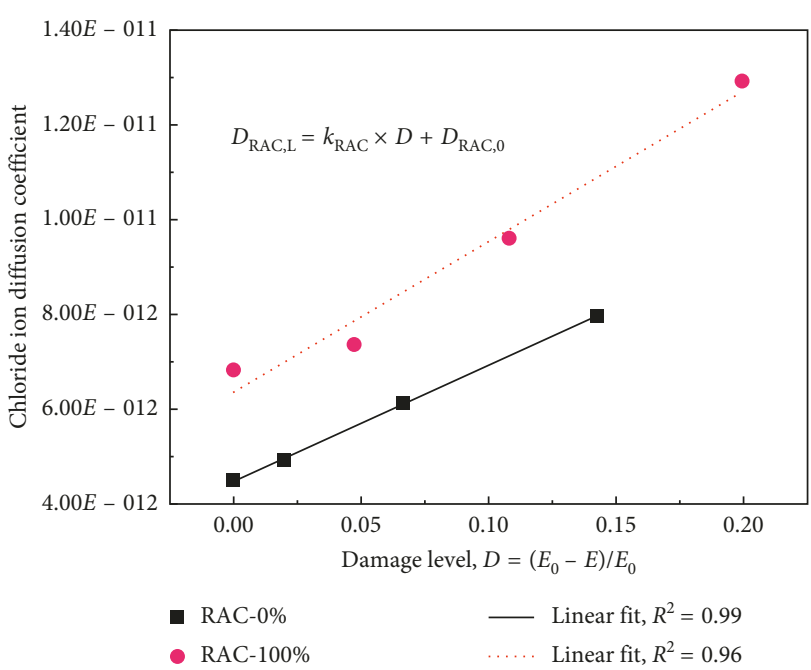

(a)

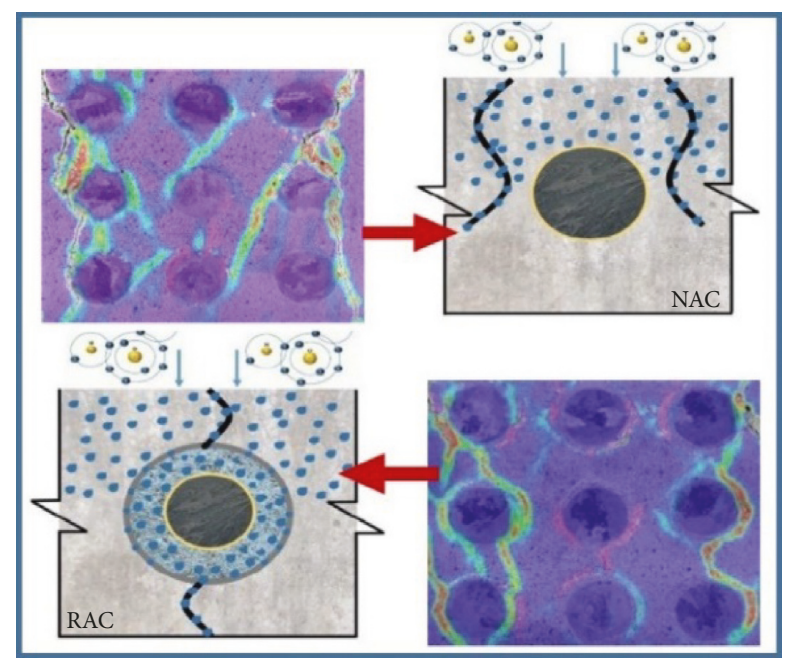

(b)

FIGURE 9: Relationship between the chloride diffusivity of RAC and the loading damage.

and without an applied load, respectively; and $k_{\mathrm{RAC}}$ presents the slope of the fitting line, which is $2 \times 10^{-11}$ and $2.3 \times 10^{-11}$ when the RA replacement percentages are $0 \%$ and $100 \%$, respectively, and the value of $k_{\mathrm{RAC}}$ with the other RA replacement percentages can be determined by the method of linear interpolation.

The results above highlight the enhancement of RAC's chloride diffusivity with the addition of RA and an increase in the applied load. The technology of digital image correlation (DIC) has been developed in recent years by using the random distribution spots on the target object to quantize the noncontacted deformation, and it is frequently used to reveal the development of cracks in concrete $[49,50]$. Using the modeled RAC method [51], this paper uses the technology of DIC to present the difference between the development of cracks in NC and RAC when subjected to a compressive loading, and the results are described in Figure 9. For the NC under a compressive loading, some of the cracks form along the natural aggregates, and most of the cracks develop along with the new mortar. For RAC under a compressive loading, almost all of the new cracks develop along the adhered old mortar, and the inferior properties of the adhered old mortar and the ITZ may further accelerate crack formation, which brings about more passageways for chloride to penetrate into RAC.

3.4. Chloride Diffusivity of RPC with Various Amounts of Preloading Damage. It can be seen from Figure 10 that the RPC damage level grows as the applied load increases. Moreover, the growth becomes more obvious when the applied load exceeds $60 \%$ of the ultimate compressive load. After suffering the same load histories, the RPC damage level increases as the RP content increases. This suggests that the partial replacement of cement by RP may improve the damage level of concrete after being subjected to the same loads. This is mainly due to the reduction in the number of hydration products as mentioned above. With the

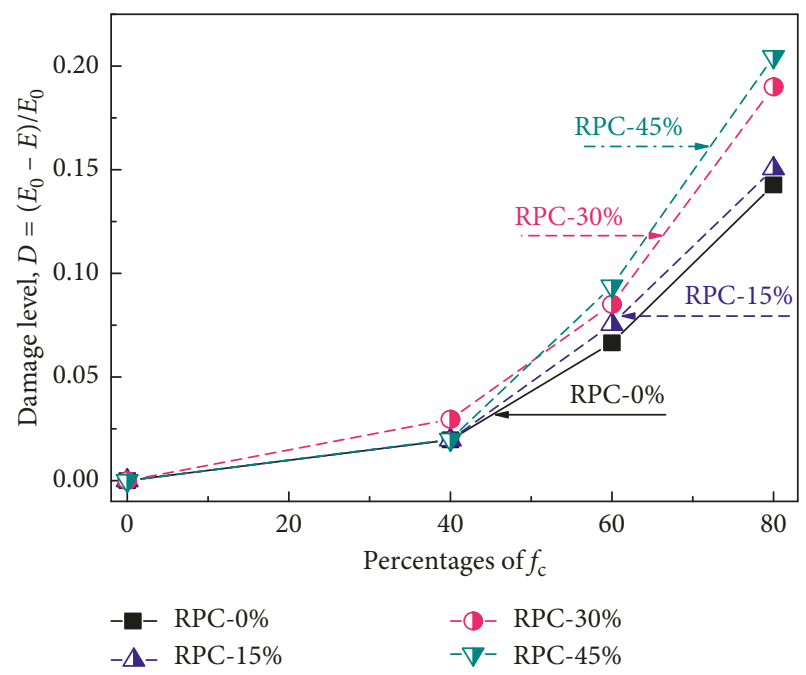

FIGURE 10: RPC damage level after suffering different applied loads.

application of a compressive load, the RPC with inferior integrity has tended to produce new cracks, and the increase in the number of cracks leads to increases in the determined sonic time as well as the damage level.

Figure 11 shows the chloride content curves and the chloride diffusion coefficient of RPC after various levels of sustained load $(0 \%, 40 \%, 60 \%$, and $80 \%$ of the ultimate compressive load). The results illustrate that the surface chloride content grows as the number of loading levels increases. The growth trend becomes more significant when the applied load exceeds $60 \%$ of the ultimate compressive load. After suffering the same load histories, the surface chloride content of RPC-30\% is lower than that of NC. For instance, the surface chloride content of RPC- $30 \%$ after $40 \%, 60 \%$, and $80 \%$ of the ultimate compressive load is approximately $0.88,0.91$, and 0.93 times higher than that of NC, respectively. The results also highlight that the chloride diffusion coefficient grows as the applied load increases. 


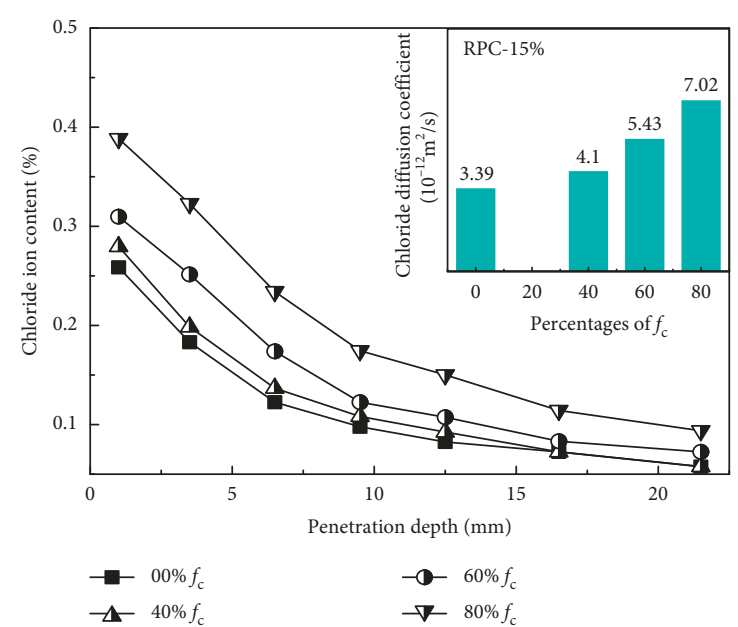

(a)

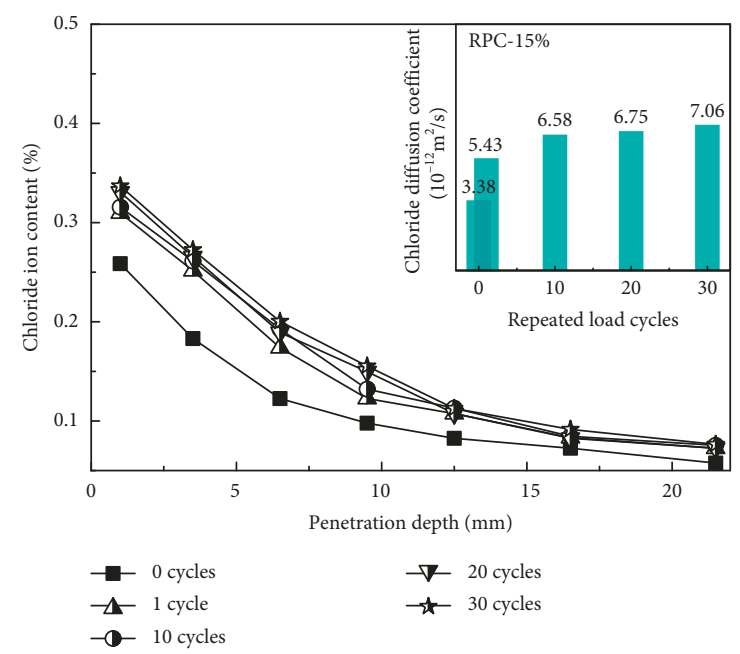

(c)

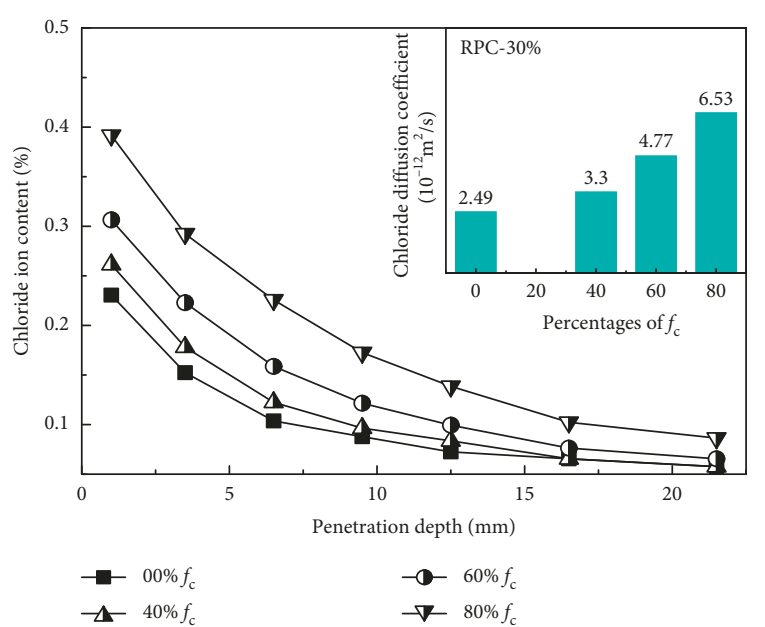

(b)

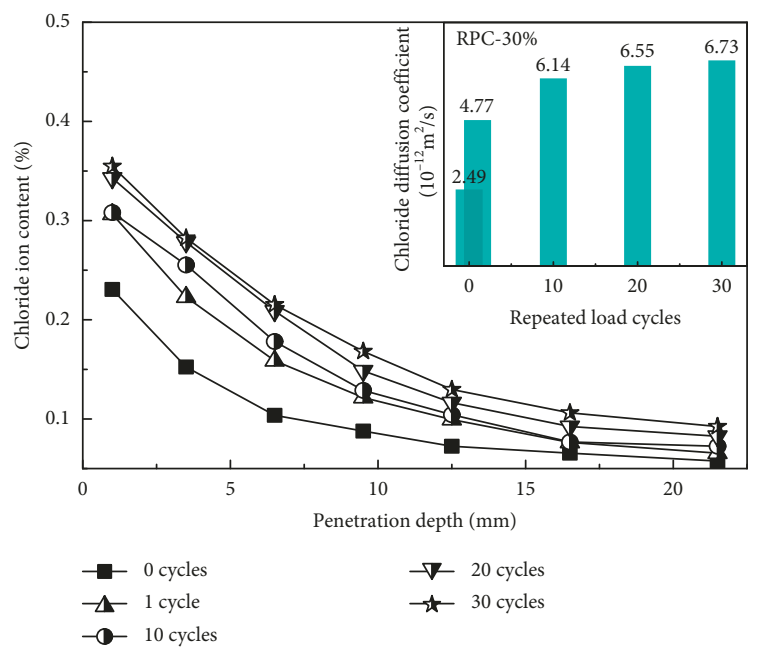

(d)

Figure 11: Chloride content curves of RPC after various loads have been applied. (a) RPC-15\% and (b) RPC-30\% after various levels of sustained load. (c) RPC-15\% and (d) RPC-30\% after various cycles of repeated load.

Figure 11 also describes the chloride content curves and the chloride diffusion coefficient of RPC after various cycles of repeated load. It can be seen that the surface chloride content and the chloride diffusion coefficient both increase as the repeated load cycles increase. Similar to RAC, the increase in the surface chloride content and the chloride diffusion coefficient is most obvious during the first repeated load cycle. However, the surface chloride content and the chloride diffusion coefficient of RPC-30\% are both lower than those of NC after the same number of repeated load cycles, which illustrates that the addition of RP reduces the concrete's chloride diffusivity. Although cracks develop with the increasing of loading levels or repeated load cycles, RPC still has a higher density than $\mathrm{NC}$ due to the filling effect of the $\mathrm{SiO}_{2}$ microparticles that RP contains, and the chloride diffusivity correspondingly decreases. Due to the addition of RP reducing the concrete's integrity and increasing its chloride diffusivity sensitivity, the difference between the chloride diffusivity of RPC-30\% and NC becomes smaller with an increase in the number of loading levels or repeated load cycles.
As regards the correlation between the chloride diffusivity of RPC and the imposed loading damage, Figure 12 shows the relationship between the chloride diffusion coefficient and the RPC damage level. The results highlight that the chloride diffusion coefficient increases linearly as the damage level grows. After suffering the same load histories, the RPC has a lower chloride diffusion coefficient than NC. The equation is also described in Figure 12, where $D_{\mathrm{RPC}, \mathrm{L}}$ and $D_{\mathrm{RPC}, 0}$, with the unit of measurement of $10^{-12} \mathrm{~m}^{2} / \mathrm{s}$, are the chloride diffusion coefficients of RPC without and with preloads, respectively; $D$ presents the damage level; $k_{\mathrm{RPC}}$ is the slope of the fitting line, which is around $2 \mathrm{E}^{-11}$.

Figure 12(b) gives the SEM images in the neat paste of RPC and NC, and a significant difference of the composition can be seen. The presence of a combination of a micropowder and C-S-H in RPC, rather than C-S-H only in $\mathrm{NC}$, and the microparticles of $\mathrm{SiO}_{2}$ that are obtained from the aggregates and brick in $\mathrm{C} \& \mathrm{D}$ wastes possesses a higher hardness and strength than C-S-H. Due to the 


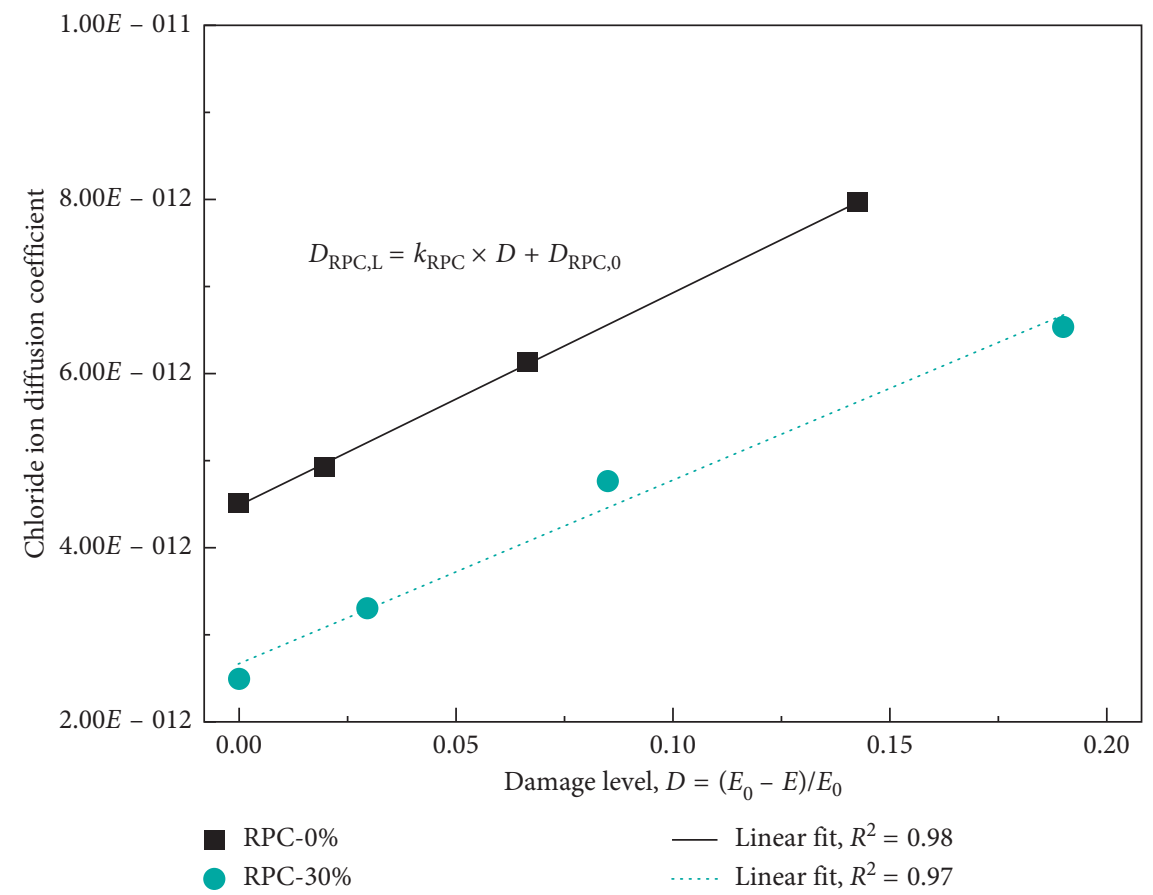

(a)

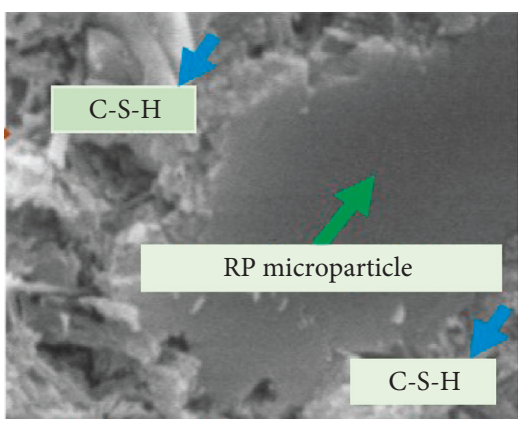

(b)

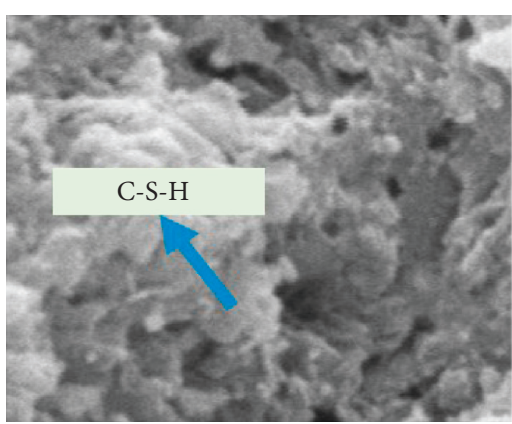

(c)

FIGURE 12: Relationship between the chloride diffusivity of RPC and the loading damage. (a) Chloride diffusivity of RPC with various damage levels. (b) SEM images for the neat paste of RPC and natural concrete.

existence of a microunit skeleton between $\mathrm{C}-\mathrm{S}-\mathrm{H}$ and the microparticles in RP, the applied loads can be wellresisted. Microcracks frequently develop in RPC, rather than relatively larger cracks that develop in NC. In addition, the microaggregate filling effect of RP can help dense the concrete that reduce the penetration of chloride ions, and thus RPC has lower chloride diffusion coefficient and surface chloride content than those of NC under the same loading condition.

Figure 13(a) shows a comparison of the chloride diffusivity of NC, RAC, and RPC with applied loads. After suffering the same load histories, RAC has a higher chloride diffusivity than NC, whereas RPC has a lower chloride diffusivity than NC. Figure 13(b) shows a comparison of the data that were obtained in this paper with those obtained by Zhang et al. [52], and the relative chloride diffusion coefficient is used to quantize the effects of applied loads on the chloride diffusivity of RAC and RPC. For NC, the impacts of preloads on the relative chloride diffusion coefficient in this paper and in the previous study are similar. For RAC and RPC, the curvatures of RAC-100\% and RPC-30\% curves are both higher than those of NC, which suggests that the addition of RA and RP increases the sensitivity of the chloride diffusivity of concrete exposed to the condition of an applied load.

Based on the wide application of RAC and RPC in practice, this paper has been developed to quantize the effects of applied loads on the chloride diffusivity of RAC and RPC, which have received little consideration in previous studies. The results highlight that the addition of RA and RP has negative and positive effects on the chloride diffusivity resistance of concrete exposed to the condition of an applied load, respectively. It can be anticipated that recycled concrete mixed with both RA and $\mathrm{RP}$ may possess a similar chloride diffusivity resistance to that of NC, which will be further investigated in the future studies. 


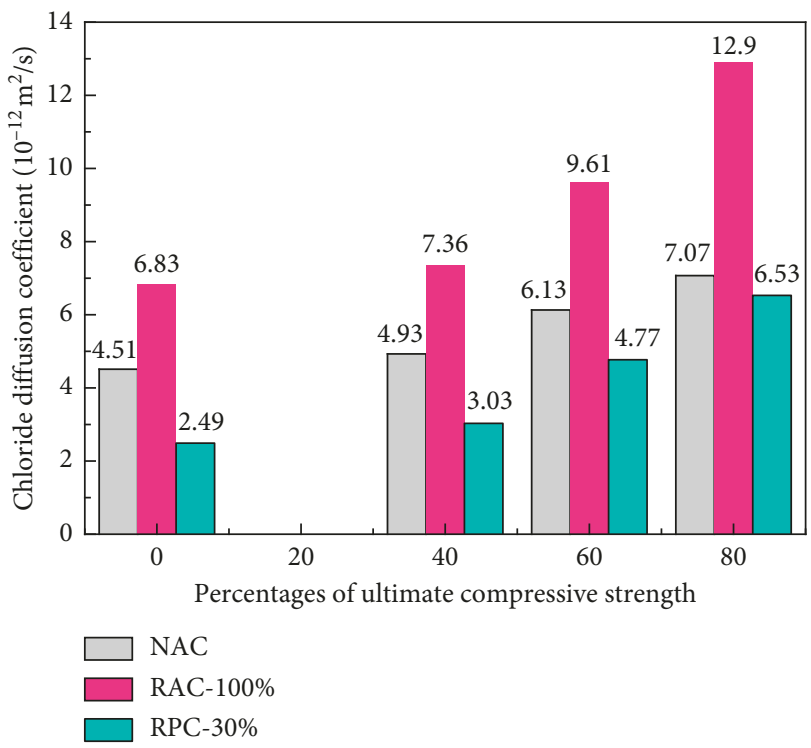

(a)

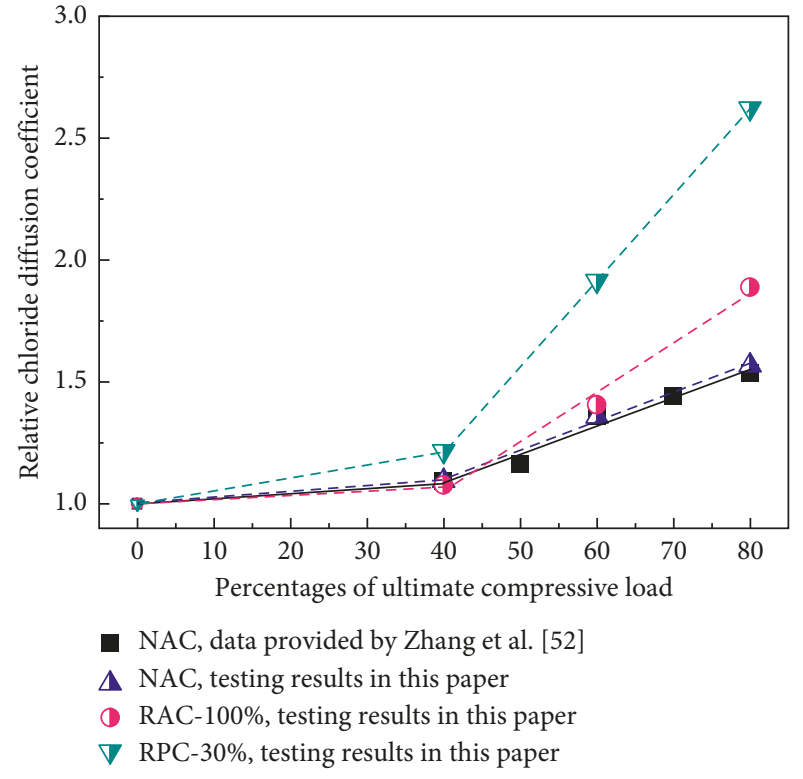

(b)

FIGURE 13: (a) A comparison of the chloride diffusivity of RAC and RPC with various applied loads. (b) A comparison of the results on chloride diffusivity in this paper with those in Zhang et al. [52].

\section{Conclusions}

This paper has investigated the effects of applied loads on the chloride penetration behavior of RAC and RPC. According to the results of this experimental work, the following conclusions can be drawn:

(1) Without an applied load, the chloride diffusivity increases with the increase of RA content, and there is a good linear relation between the chloride diffusivity and the RA replacement percentage in concrete. RPC has a lower chloride diffusivity than NC. After suffering the same load histories, the chloride diffusivity decreases with the increase of $\mathrm{RP}$ replacement percentage when the RP content is below $30 \%$, whereas the chloride diffusivity raises with a further increase in RP content in concrete.

(2) When exposed to applied load, the chloride diffusivity of RAC and RPC both increased with an increase in the applied loads or the repeated load cycles, and the increasing rate of RAC and RPC is higher than that of NC. After suffering from the same load histories, the chloride diffusivity of RAC is much higher than that of NC; however, the chloride diffusivity of RPC is still lower than that of NC.

(3) After suffering from the same loading levels, the increasing rates of the chloride diffusion coefficient of RAC and RPC are both higher than that of NC, which indicates that the addition of RA and RP improves the chloride diffusivity sensitivity of concrete under an applied load condition. In particular, the chloride diffusion coefficient increases linearly with the increasing of induced loading damage for RAC and RPC, and the related equations can be used to quantify the chloride penetration behavior of RAC and RPC by the values of induced loading damage.

(4) The chloride penetration test was carried out on the specimens after unloading in this study, whereas the chloride penetration into RAC and RPC is frequent along with the sustained loading, which should be investigated in the future. The lower applied loads (below $40 \% f_{\mathrm{c}}$ ) and the higher applied loads (above $80 \% f_{\mathrm{c}}$ ) should also been considered. Considering the negative impact of RA and the positive impact of RP on the chloride penetration behavior, the effects of the applied loads on the chloride penetration behavior of recycled concrete mixed with both RA and RP would be investigated in the further studies.

\section{Data Availability}

The data used to support the findings of this study are available from the corresponding author upon request.

\section{Conflicts of Interest}

The authors declare that they have no conflicts of interest.

\section{Acknowledgments}

The authors gratefully acknowledge substantial support of ongoing projects from the National Natural Science Foundation of China (51708419), Shanghai Pujiang Talent Fund (17PJ1409500), National Key Research and Development Program (2018YFD1101002), and Fundamental Research Funds for the Central Universities, National College Students Innovation and Entrepreneurship Training Program (201710349022). 


\section{References}

[1] A. Petcherdchoo, "Probability-based sensitivity of service life of chloride-attacked concrete structures with multiple cover concrete repairs," Advances in Civil Engineering, vol. 2018, Article ID 4525646, 17 pages, 2018.

[2] Z. Ma, F. Zhu, and G. Ba, "Effects of freeze-thaw damage on the bond behavior of concrete and enhancing measures," Construction and Building Materials, vol. 196, pp. 375-385, 2019.

[3] P. Zhang, F. H. Wittmann, M. Vogel, H. S. Müller, and T. Zhao, "Influence of freeze-thaw cycles on capillary absorption and chloride penetration into concrete," Cement and Concrete Research, vol. 100, pp. 60-67, 2017.

[4] P. Zhang, D. Li, Y. Qiao, S. Zhang, C. Sun, and T. J. Zhao, "Effect of air entrainment on the mechanical properties, chloride migration, and microstructure of ordinary concrete and fly ash concrete," Journal of Materials in Civil Engineering, vol. 30, no. 10, 2018.

[5] Z. M. Ma, G. Z. Ba, and Z. H. Duan, "Effects of high temperature and cooling pattern on the chloride permeability of concrete," Advances in Civil Engineering, vol. 2019, Article ID 2465940, 13 pages, 2019.

[6] M. A. El-Reedy, Steel-Reinforced Concrete Structures: Assessment and Repair of Corrosion, CRC Press, Boca Raton, FL, USA, 2017.

[7] Y. Cao, C. Gehlen, U. Angst, L. Wang, Z. Wang, and Y. Yao, "Critical chloride content in reinforced concrete-an updated review considering Chinese experience," Cement and Concrete Research, vol. 117, pp. 58-68, 2019.

[8] J. Osio-Norgaard, J. P. Gevaudan, and W. V. Srubar, “A review of chloride transport in alkali-activated cement paste, mortar, and concrete," Construction and Building Materials, vol. 186, pp. 191-206, 2018.

[9] H. Wang, C. Lu, W. Jin, and Y. Bai, "Effect of external loads on chloride transport in concrete," Journal of Materials in Civil Engineering, vol. 23, no. 7, pp. 1043-1049, 2011.

[10] Z. M. Ma, T. J. Zhao, J. Z. Xiao, and P. G. Wang, "Effect of applied loads on water and chloride penetrations of strain hardening cement-based composites," Journal of Materials in Civil Engineering, vol. 28, pp. 1-9, 2014.

[11] C. C. Lim, N. Gowripalan, and V. Sirivivatnanon, "Microcracking and chloride permeability of concrete under uniaxial compression," Cement and Concrete Composites, vol. 22, no. 5, pp. 353-360, 2000.

[12] M. Saito and H. Ishimori, "Chloride permeability of concrete under static and repeated compressive loading," Cement and Concrete Research, vol. 25, no. 4, pp. 803-808, 1995.

[13] S. Q. He and J. X. Gong, "Influence of flexural loading on permeability of chloride ion in concrete," Journal of Building Materials, vol. 2, pp. 134-138, 2005.

[14] H. Ye, C. Fu, N. Jin, and X. Jin, "Influence of flexural loading on chloride ingress in concrete subjected to cyclic dryingwetting condition," Computers and Concrete, vol. 15, no. 2, pp. 183-198, 2015.

[15] J. Xu and F. Li, "Analytical model for load dependence of chloride penetration into concrete," Journal of Materials in Civil Engineering, vol. 29, no. 5, article 04016279, 2016.

[16] P. Zhang, F. H. Wittmann, P. Lura, H. S. Müller, S. Han, and T. Zhao, "Application of neutron imaging to investigate fundamental aspects of durability of cement-based materials: a review," Cement and Concrete Research, vol. 108, pp. 152$166,2018$.
[17] J. Xu and F. Li, "A meso-scale model for analyzing the chloride diffusion of concrete subjected to external stress," Construction and Building Materials, vol. 130, pp. 11-21, 2017.

[18] A. K. Saha and P. K. Sarker, "Durability of mortar incorporating ferronickel slag aggregate and supplementary cementitious materials subjected to wet-dry cycles," International Journal of Concrete Structures and Materials, vol. 12, no. 1, p. 29, 2018.

[19] P. Zhang, Y. Dai, X. Ding, C. Zhou, X. Xue, and T. Zhao, "Selfhealing behaviour of multiple microcracks of strain hardening cementitious composites (SHCC)," Construction and Building Materials, vol. 169, pp. 705-715, 2018.

[20] A. K. Saha and P. K. Sarker, "Durability characteristics of concrete using ferronickel slag fine aggregate and fly ash," Magazine of Concrete Research, vol. 70, no. 17, pp. 865-874, 2018.

[21] S. I. Ahmad and M. Rahman, "Mechanical and durability properties of induction-furnace-slag-incorporated recycled aggregate concrete," Advances in Civil Engineering, vol. 2018, Article ID 3297342, 11 pages, 2018.

[22] J. Xiao, Z. Ma, T. Sui, A. Akbarnezhad, and Z. Duan, "Mechanical properties of concrete mixed with recycled powder produced from construction and demolition waste," Journal of Cleaner Production, vol. 188, pp. 720-731, 2018.

[23] P. Mercader-Moyano and A. Ramírez-de-Arellano-Agudo, "Selective classification and quantification model of C\&D waste from material resources consumed in residential building construction," Waste Management \& Research, vol. 31, no. 5, pp. 458-474, 2013.

[24] N. Seror, S. Hareli, and B. A. Portnov, "Evaluating the effect of vehicle impoundment policy on illegal construction and demolition waste dumping: Israel as a case study," Waste Management, vol. 34, no. 8, pp. 1436-1445, 2014.

[25] J. Xiao, Z. Ma, and T. Ding, "Reclamation chain of waste concrete: a case study of Shanghai," Waste Management, vol. 48, pp. 334-343, 2016.

[26] K. N. Rahal and Y. T. Alrefaei, "Shear strength of recycled aggregate concrete beams containing stirrups," Construction and Building Materials, vol. 191, pp. 866-876, 2018.

[27] R. V. Silva, J. de Brito, and R. K. Dhir, "Establishing a relationship between modulus of elasticity and compressive strength of recycled aggregate concrete," Journal of Cleaner Production, vol. 112, pp. 2171-2186, 2016.

[28] W. Z. Taffese, "Suitability investigation of recycled concrete aggregates for concrete production: an experimental case study," Advances in Civil Engineering, vol. 2018, Article ID 8368351, 11 pages, 2018.

[29] B. Cantero, I. F. Sáez del Bosque, A. Matías, and C. Medina, "Statistically significant effects of mixed recycled aggregate on the physical-mechanical properties of structural concretes," Construction and Building Materials, vol. 185, pp. 93-101, 2018.

[30] M. Bravo, J. De Brito, J. Pontes, and L. Evangelista, “Durability performance of concrete with recycled aggregates from construction and demolition waste plants," Construction and Building Materials, vol. 77, pp. 357-369, 2015.

[31] R. Neves, A. Silva, J. De Brito, and R. V. Silva, "Statistical modelling of the resistance to chloride penetration in concrete with recycled aggregates," Construction and Building Materials, vol. 182, pp. 550-560, 2018.

[32] J. K. Yong and W. C. Yun, "Utilization of waste concrete powder as a substitution material for cement," Construction and Building Materials, vol. 30, pp. 500-504, 2012. 
[33] Z. Ma, W. Li, H. Wu, and C. Cao, "Chloride permeability of concrete mixed with activity recycled powder obtained from C\&D waste," Construction and Building Materials, vol. 199, pp. 652-663, 2019.

[34] P. Zhang, D. Hou, Q. Liu, Z. Liu, and J. Yu, "Water and chloride ions migration in porous cementitious materials: an experimental and molecular dynamics investigation," Cement and Concrete Research, vol. 102, pp. 161-174, 2017.

[35] Q. Gao, Z. M. Ma, J. Z. Xiao, and F. A. Li, "Effects of imposed damage on the capillary water absorption of recycled aggregate concrete," Advances in Materials Science and Engineering, vol. 2018, Article ID 2890931, 12 pages, 2018.

[36] Y. Kim, A. Hanif, S. M. S. Kazmi, M. J. Munir, and C. Park, "Properties enhancement of recycled aggregate concrete through pretreatment of coarse aggregates-comparative assessment of assorted techniques," Journal of Cleaner Production, vol. 191, pp. 339-349, 2018.

[37] A. Akbarnezhad, K. C. G. Ong, M. H. Zhang, and C. T. Tam, "Acid treatment technique for determining the mortar content of recycled concrete aggregates," Journal of Testing and Evaluation, vol. 41, no. 3, pp. 441-450, 2013.

[38] W. V. Srubar, "Stochastic service-life modeling of chlorideinduced corrosion in recycled-aggregate concrete," Cement and Concrete Composites, vol. 55, pp. 103-111, 2015.

[39] W. Wang, C. Lu, G. Yuan, and Y. Zhang, "Effects of pore water saturation on the mechanical properties of fly ash concrete," Construction and Building Materials, vol. 130, pp. 54-63, 2017.

[40] M. A. Meyers, Dynamic Behavior of Materials, John Wiley \& Sons, Hoboken, NJ, USA, 1994.

[41] A. D. Tegguer, S. Bonnet, A. Khelidj, and V. Baroghel-Bouny, "Effect of uniaxial compressive loading on gas permeability and chloride diffusion coefficient of concrete and their relationship," Cement and Concrete Research, vol. 52, pp. 131139, 2013.

[42] T. Luping and J. Gulikers, "On the mathematics of timedependent apparent chloride diffusion coefficient in concrete," Cement and Concrete Research, vol. 37, no. 4, pp. 589-595, 2007.

[43] C. Andrade, "Calculation of chloride diffusion coefficients in concrete from ionic migration measurements," Cement and Concrete Research, vol. 23, no. 3, pp. 724-742, 1993.

[44] B. Hu, B. Liu, and L. Zhang, "Chloride ion permeability test and analysis for recycled concrete," Journal of Hefei University of Technology (Natural Science), vol. 32, pp. 1240-1243, 2009.

[45] H. Qin and Y. Yang, "Influence of the interfacial transition zone on anti chloride ion permeability of recycled concrete," Highway Engineering, vol. 41, pp. 70-74, 2016.

[46] L. Wang and S. Li, "Capillary absorption of concrete after mechanical loading," Magazine of Concrete Research, vol. 66, no. 8, pp. 420-431, 2014.

[47] B. Qi, J. Gao, F. Chen, and D. Shen, "Chloride penetration into recycled aggregate concrete subjected to wetting-drying cycles and flexural loading," Construction and Building Materials, vol. 174, pp. 130-137, 2018.

[48] P. H. Sun, Experimental Study on Permeability of Concrete under Cyclic Loadings, Dalian University of Technology, Dalian, China, Master Dissertation, 2012.

[49] Y. Y. Han, N. S. Liu, and Y. C. Cai, "Application of digital image correlation (DIC) method in experimental research on compression damage of concrete," Concrete, vol. 37, pp. 5155, 2015.

[50] Y. J. Zhao, Y. M. Dou, and L. J. Cui, "Investigation of the reinforced concrete crack propagation law based on the DIC method," Concrete, vol. 5, pp. 1-4, 2017.
[51] J. Xiao, W. Li, D. J. Corr, and S. P. Shah, "Effects of interfacial transition zones on the stress-strain behavior of modeled recycled aggregate concrete," Cement and Concrete Research, vol. 52, pp. 82-99, 2013.

[52] L. Zhang, J. Jia, G. Meng, and W. Zhu, "Chloride diffusion in concrete subjected to compressive loading," Magazine of Concrete Research, vol. 66, no. 19, pp. 991-997, 2014. 


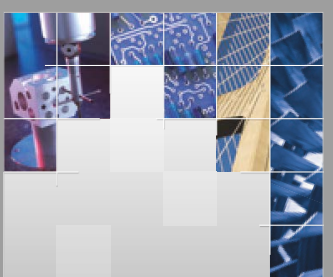

\section{Enfincering}
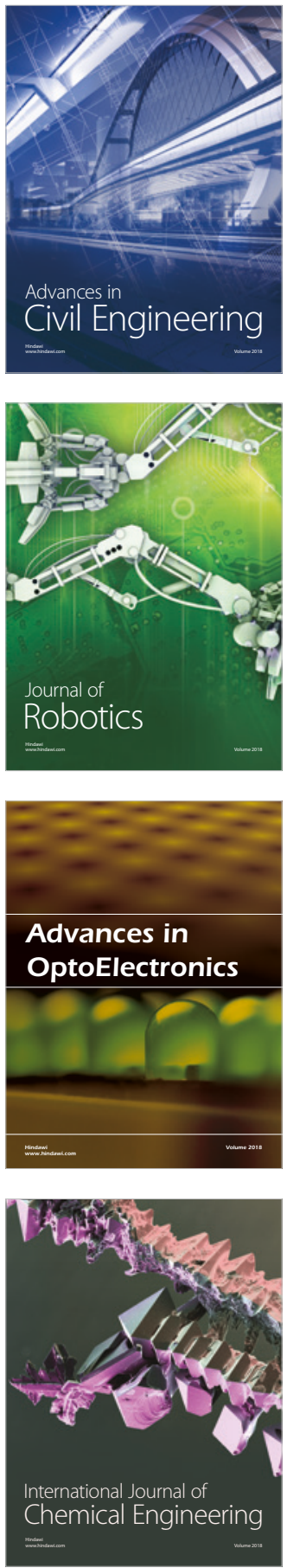

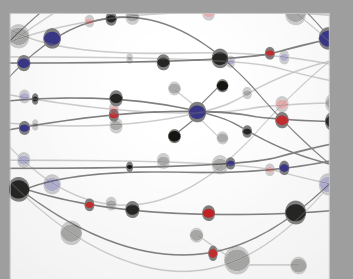

\section{Rotating \\ Machinery}

The Scientific World Journal

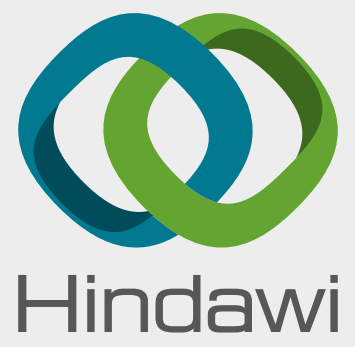

Submit your manuscripts at

www.hindawi.com
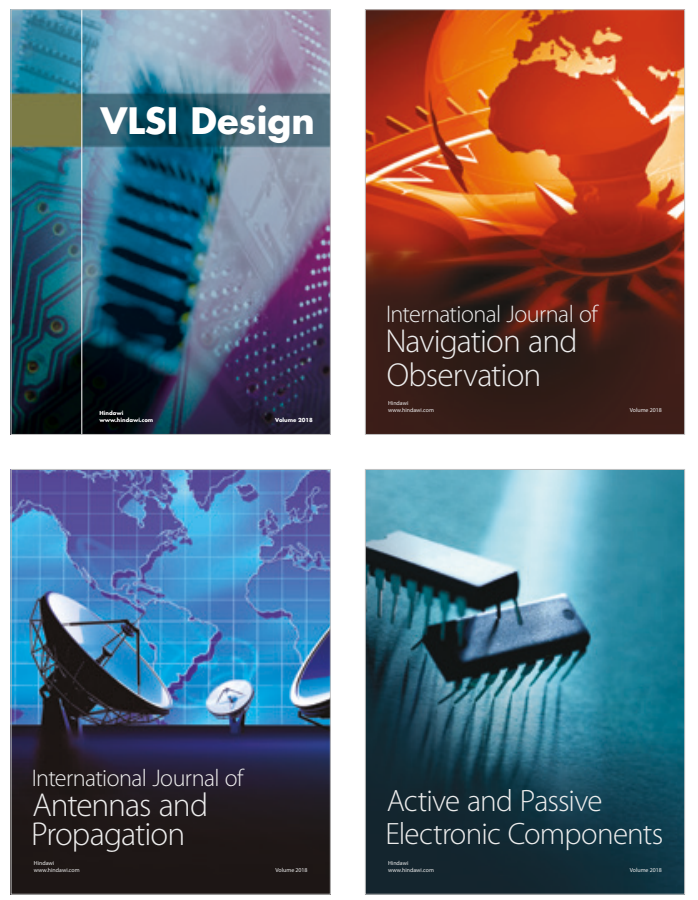
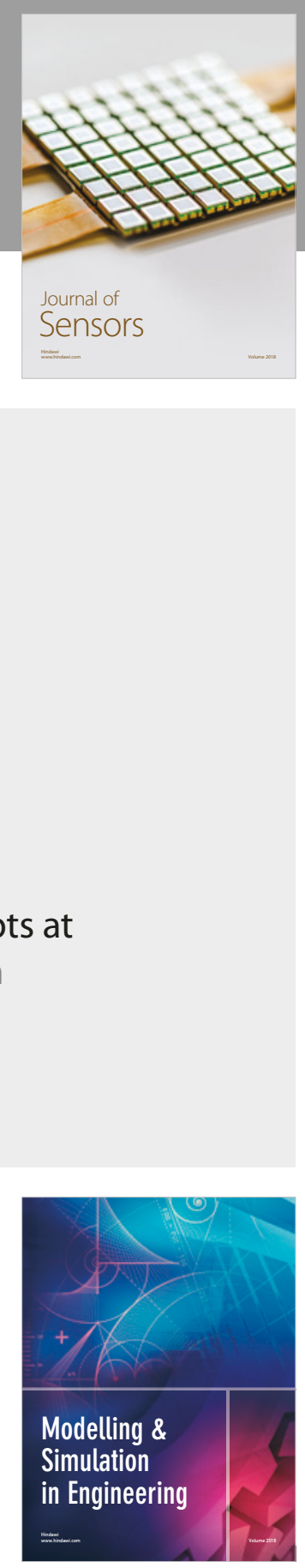

\section{Advances \\ Multimedia}
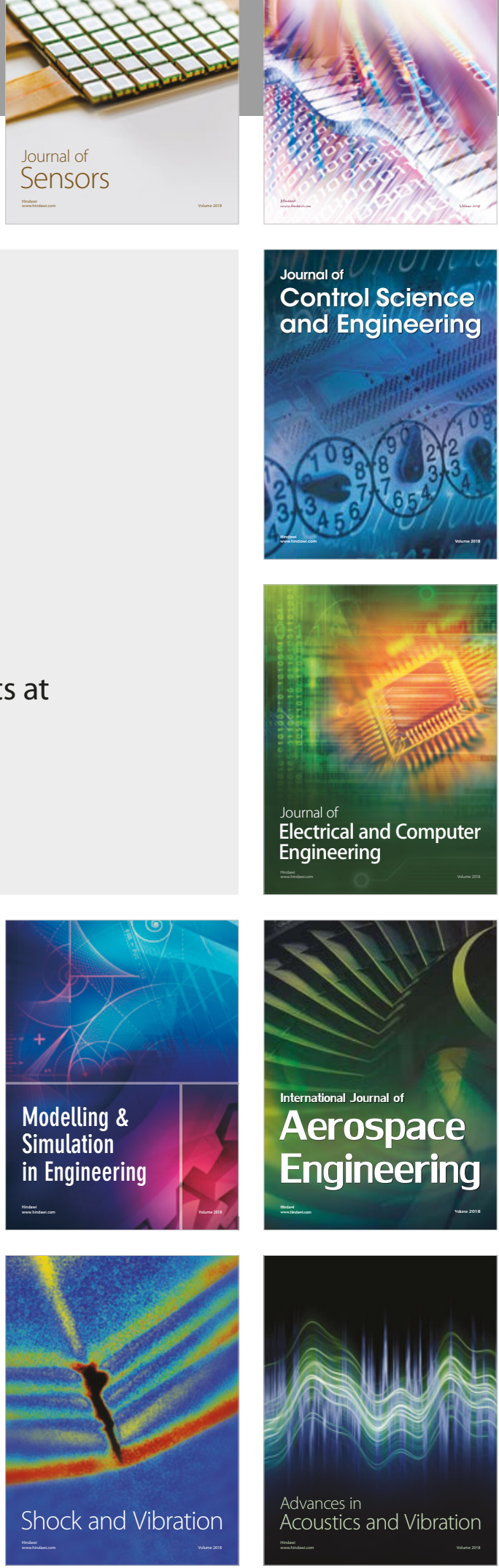